\title{
Phân tích tổng hợp: Mối tương quan giữa tính chất methyl hóa vượt mức vùng promoter gen GSTP1 (Glutathione S-Transferase P1) với bệnh ung thư vú
}

\section{Meta-analysis: Association between promoter hypermethylation of Glutathione S-Transferase P1 (GSTP1) and breast cancer}

\author{
Trương Kim Phượng ${ }^{1 *}$, Phạm Hoàng Năng ${ }^{1}$, Lao Đức Thuận ${ }^{1}$, Lê Huyền Ái Thúy ${ }^{1}$ \\ ${ }^{1}$ Trường Đại học Mở Thành phố Hồ Chí Minh, Việt Nam \\ "Tác giả liên hệ, Email: phuong.tk@ou.edu.vn
}

THÔNG TIN

DOI:10.46223/HCMCOUJS. tech.vi.13.1.799.2018

Ngày nhận: 19/01/2018

Ngày nhận lại: 12/02/2018

Duyệt đăng: 14/03/2018

Tù khóa:

GSTP1, methyl hóa, phân tích tổng hợp, ung thư vú
TÓM TẮT

Mối tương quan giữa tính chất methyl hóa vượt mức vùng promoter gen GSTPl đối với bệnh ung thư vú đã được công bố trong nhiều công trình nghiên cứu khác nhau tại nhiều quốc gia trên thế giới. Dù vậy, tính tương quan giữa tính chất epigenetic này của gen với bệnh ung thư vú không thống nhất qua từng công bố. Do đó chúng tôi thực hiện phân tích tổng hợp này nhằm xác nhận có hay không mối tương quan giữa tính chất methyl hóa vượt mức vùng promoter gen GSTPl đối với bệnh ung thư vú. Phân tích 19 nghiên cứu (ca-chứng) về tính chất methyl hóa vượt mức vùng promoter của gen $G S T P 1$ đối với bệnh ung thứ vú (1910 ca bệnh ung thư, 671 người lành) cho thấy tính chất methyl hóa vùng promoter gen GSTP1 làm tăng nguy cơ ung thư vú (OR = 10,497; 95\%CI = 4,42 - 24,94; P < 0,0001; Mô hình phân tích ảnh hưởng ngẫu nhiên). Mối tương quan tính trên chỉ số nguy cơ OR tăng khi chọn lọc lại 13 nghiên cứu (1247 ca bệnh ung thư, 369 người lành $), \mathrm{OR}=13,642(95 \% \mathrm{CI}=8,23-22,60 ; \mathrm{P}<0,001$; Mô hình phân tích ảnh hưởng bất biến). Khi tách các phân hạng, chỉ số tương quan tăng: tính chất methyl hóa vượt mức vùng promoter gen GSTP1 xuất hiện ở cả mẫu mô và mẫu máu, tính chất methyl hóa vượt mức này nên được xác định bằng phương pháp Methylation Specific $\mathrm{PCR}$ và các phương pháp khác như Pyrosequencing, MS-MLPA, Methylight và QMSP, so với Bisulfite methylation specific PCR. Methyl hóa vượt mức vùng promoter gen GSTP1 xuất hiện cao ở các chủng tộc châu Âu, Phi so với châu Á. Ngoài ra, tính chất methyl hóa vượt mức vùng promoter gen GSTPI cũng là tính đặc trưng của bệnh nhân ung thư vú có phân độ mô học cao, giai đoạn bệnh muộn, kích thước khối u lớn, có sự xuất hiện hạch bạch huyết và Her2. Sự methyl 
hóa vượt mức vùng promoter gen GSTPl cũng chính là nguyên nhân làm giảm hàm lượng và chức năng protein GSTP1.

\begin{tabular}{|c|}
\hline The accociation hetween prometer \\
\hline $\begin{array}{l}\text { The association between promoter hypermethylation of } \\
\text { Glutathione S-transferase P1 (GSTP1) and breast cancer has been } \\
\text { investigated by much previous research worldwide. However, the } \\
\text { results of the correlation between the epigenetic features of } \\
\text { human genes with breast cancer varied from study to study. The } \\
\text { purpose of this study, therefore, is to use a meta-analysis to } \\
\text { identify how the GSTP1 gene's promoter hypermethylation and } \\
\text { breast cancer correlate to each other. Accordingly, } 19 \text { case- } \\
\text { control studies were conducted to evaluate the association } \\
\text { between GSTP gene' promoter methylation status and breast } \\
\text { cancer, including } 1910 \text { cancer cases and } 671 \text { control cases. The } \\
\text { findings showed that the status of gene promoter methylation } \\
\text { increased the candidate's breast cancer risk by calculating the OR } \\
\text { value (OR = } 10,497 ; 95 \% \text { CI } 4.42-24.94 \text {; P } 0.0001 \text {; Random- } \\
\text { effect meta-analysis). In addition, the re-collection of } 13 \text { case- } \\
\text { control studies, including } 1247 \text { cancer cases and } 369 \text { control case, } \\
\text { also showed an increase in the OR value (OR = } 13,642 \text {; } 95 \% \text { I } \\
=8.23 \text { - } 22.60 ; \text { P }<0,001 \text {, Fixed-effect meta-analysis model). The } \\
\text { association value also increased. Then, the hypermethylation } \\
\text { characteristic of the GSTP1 gene's promoter was observed in } \\
\text { both tissue and blood samples, and at this level, it should be } \\
\text { detected by many methods such as Methylation Specific PCR, } \\
\text { MS-MLPA, Methylight and QMSP compared to Bisulfite } \\
\text { methylation-specific PCR. The hypermethylated GSTP1 } \\
\text { promoter was higher in Europeans and Africans than in Asians. } \\
\text { Moreover, the hypermethylated GSTP1 gene's promoter is also } \\
\text { found in breast cancer patients with high histopathology, large } \\
\text { tumor size, lymph node and HER } 2 \text { and at the terminal stage of } \\
\text { the disease. The hypermethylated } G S T P 1 \text { gene's promoter also } \\
\text { results in the reduced expression and activity of GSTP1 protein. }\end{array}$ \\
\hline
\end{tabular}

analysis, methylation

\section{Tổng quan}

Ung thư vú, một trong những bệnh ung thư có tỷ suất mắc cao ở giới nữ, xấp xỉ $25 \%$ trong tổng số trường hợp mắc các ung thư khác nhau, và là nguyên nhân gây tử vong cao nhất ở giới nữ (Ferlay et al., 2015; Globocan, 2012). Nhiều công trình nghiên cứu đã cho thấy hiện tượng epigenetics, đặc biệt là methyl hóa DNA vượt mức tại các đảo $\mathrm{CpG}$ trên vùng promoter của các gen đè nén u (Tumor Suppressor Genes - TSG) dẫn đến sự bất hoạt của các gen này; từ đó kích hoạt cơ chế sinh u, trong đó có ung thư vú (Jones \& Baylin, 2002; Terry, McDonald, 
Wu, Eng, \& Santella, 2016). Tuy nhiên, vẫn tồn tại sự khác nhau trong các công bố về tính tương quan giữa methyl hóa vượt mức với các đặc điểm khác liên quan đến bệnh như nguồn mẫu sử dụng cho phân tích, phương pháp phân tích, chủng tộc được nghiên cứu, ... (Jung et al., 2013; Müller et al., 2003; Park et al., 2010; Phuong, Thao, Thuan, \& Thuy, 2016; Sturgeon et al., 2012; Wu et al., 2016).

Trong những năm gần đây, một số TSG (Tumor Suppressor Gene - Gen đè nén u) đã được xác định là gen tiềm năng nhạy cảm với ung thư vú và một trong số đó là gen Glutathione S-transferase P1 (GSTP1) (Tang et al., 2015). GSTP1 (Glutathione S-transferase pi 1) là thành viên của họ enzyme Glutathione $\mathrm{S}$ - transferases (GSTs), định vị trên nhiễm sắc thể số 11 (11q13) (Genbank), có kích thước 3.059bp, gồm 7 exon (GeneCards, NCBI). Gen GSTP1 mã hóa protein GSTP1 với một số chức năng chính như giải độc và kiểm soát sự chết theo chu trình (Isgor \& Isgor, 2011; Wang, Arifoglu, Ronai, \& Tew, 2001).

Chúng tôi thực hiện phân tích tổng hợp (Meta-analysis) này trên một khối dữ liệu tương đối lớn được tổng hợp từ số liệu của nhiều công bố khoa học trên thế giới (cập nhật đến tháng 1/2018), nhằm phản ánh một cách chính xác hơn về mối tương quan giữa methyl hóa vượt mức vùng promoter gen $G S T P 1$ với các đặc điểm đặc trưng của bệnh ung thư vú.

\section{Vật liệu - Phương pháp nghiên cứu}

\subsection{Thu thập các công bố khoa học}

Nguồn dữ liệu được thu thập là các công bố khoa học thuộc dạng dữ liệu gốc trên nguồn cơ sở dữ liệu trực tuyến: PubMed, EMBASE và Web of Science bằng một số từ khóa: “GSTP1 ”, "breast cancer”, "DNA hypermethylation”; số liệu cập nhật đến tháng 1 năm 2018.

\subsection{Tiêu chuẩn chọn lọc các công bố khoa học}

Các công bố khoa học được chọn vào phân tích tổng hợp theo một số tiêu chuẩn như sau: (1) Nghiên cứu ca-chứng (case-control study); Nghiên cứu đoàn hệ (cohort study) trong khảo sát tính tương quan giữa methyl hóa vượt mức vùng promoter gen GSTP1 với các đặc điểm lâm sàng: phân độ mô học, giai đoạn bệnh,...; (2) Dữ liệu đo lường mức độ tương quan giữa yếu tố nguy cơ (tính chất methyl hóa vượt mức trên gen GSTP1) và nguy cơ mắc bệnh ung thư vú, thông qua chỉ số nguy cơ tỷ suất chênh (Odds Ratio - OR) với khoảng tin cậy $95 \%$ (Confidence intervals- $\mathrm{CIs}$ )*; (3) các công bố khoa học được viết bằng tiếng Anh; (4) các công bố tiến hành trên mẫu bệnh phẩm của bệnh nhân nữ giới. Không thỏa các yêu cầu trên, ví dụ như nghiên cứu tiến hành trên mô động vật; dòng tế bào nuôi cấy; bệnh ung thư khác; hoặc đối tượng mục tiêu (gen mục tiêu) khác và các báo cáo tổng quan (review) đều bị loại bỏ.

*Dũ liệu OR này được các công bố xuất bản hoặc chúng tôi tính bằng phần mềm

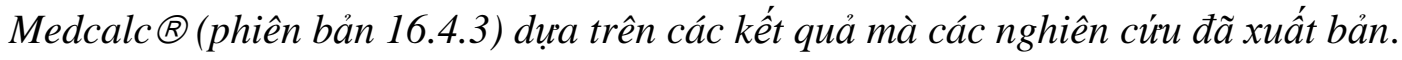

\subsection{Trích xuất dũ liệu}

Sau bước chọn lọc các công bố, dữ liệu được trích xuất bao gồm: tác giả, năm xuất bản, thông tin về bệnh nhân: chủng tộc, kiểu nghiên cứu ca-chứng, nghiên cứu đoàn hệ, phương pháp phân tích tính chất methyl hóa, tần số methyl hóa gen GSTP1, trên mẫu bệnh và mẫu 
chứng, các đặc điểm lâm sàng như giai đoạn bệnh, phân độ mô học, kích thước khối u, sự xuất hiện hạch bạch huyết, sự biểu hiện của thụ thể Her2.

\subsection{Phân tích thống $k \hat{e}$}

Phân tích thống kê được tiến hành theo mô hình phân tích tổng hợp ảnh hưởng bất biến (Fixed-effects meta-analysis) hoặc mô hình phân tích tổng hợp ảnh hưởng ngẫu nhiên (Random effects meta-analysis) cho một tiêu chí nhị phân (a dichotomous outcome) với khoảng tin cậy $95 \%$ (CI) nhằm đánh giá tính tương quan giữa yếu tố nguy cơ (tính chất methyl hóa vượt mức vùng promoter gen $G S T P 1$ và/hoặc tính chất đa hình đơn nucleotide) và nguy cơ mắc bệnh ung thư vú. Ước tính chỉ số bất đồng nhất (Index of Heterogeneity $\mathrm{I}^{2}$ ) giữa các nghiên cứu được tiến hành dựa vào thuật Chi bình phương. Giá trị $\mathrm{I}^{2}$ được xác định theo thang từ 0 đến $100 \%$ theo công bố của Higgins, Thompson, Deeks, và Altman (2003) cũng như hướng dẫn của Ryan (2014) và hệ thống Cochrane, bao gồm tính bất đồng nhất thấp $\left(0 \%<\mathrm{I}^{2}<40 \%\right)$, tính bất đồng nhất vừa $\left(30 \%<\mathrm{I}^{2}<60 \%\right)$, tính bất đồng nhất cao $\left(50 \%<\mathrm{I}^{2}<90 \%\right)$ và tính bất đồng nhất đáng kể $\left(\mathrm{I}^{2}>75 \%\right)$. Khi ước tính chỉ số đồng nhất (Index of homogeneity - $\mathrm{Q}$ ) có giá trị $\mathrm{P} \geq 0,1$ và giá trị $\mathrm{I}^{2}<50 \%$, điều này cho thấy không có tính bất đồng nhất giữa các công trình nghiên cứu, mô hình phân tích tổng hợp ảnh hưởng bất biến theo phương pháp của Mantel-Haenszel (Cochrane, 2014) sẽ được áp dụng nhằm phân tích chỉ số tỷ suất chênh (Odds Ratio - OR) với giá trị trọng số dựa trên nguồn dữ liệu đã được nhận vào phân tích tổng hợp. Ngược lại, khi chỉ số đồng nhất có giá trị $\mathrm{P}<0,1$ và giá trị $\mathrm{I}^{2}>50 \%$, điều này cho thấy có tính bất đồng nhất giữa các công trình nghiên cứu, mô hình phân tích tổng hợp ảnh hưởng bất biến theo phương pháp của DerSimonian (Cochrane, 2014) sẽ được áp dụng. Thêm vào đó, sự phân tích sẽ được tiếp tục tiến hành nhằm xác định tính bất đồng nhất trên các yếu tố, bao gồm chủng tộc: $00 \mathrm{C} 1$, Phi, và Da trắng (bao gồm châu Âu, Úc và Mỹ) (Ford \& Kelly, 2005; Senior \& Bhopal, 1994); loại mẫu bệnh phẩm: mẫu máu hay mô; phương pháp xác định methyl hóa DNA: MSP (Methylation specific PCR, là phương pháp chiếm đa số) so với các phương pháp khác (QMSP - Quantitative MSP, Bisulfite specific PCR - BSP, ...). Tất cả phân tích thống kê được thực hiện trên phần mềm Medcalc $\mathbb{R}$ (phiên bản 16.4.3).

\section{Kết quả và thảo luận}

\subsection{Khai thác dũ liệu}

Dựa vào hướng dẫn của hệ thống PRISMA (Moher, Liberati, Tetzlaff, Altman, \& Prisma Group, 2009) và Cochrane cùng với một số công bố khoa học của Haidich (2010), Russo (2007), Hughes (1996), quy trình lựa chọn, đánh giá công trình nghiên cứu, loại bỏ và trích xuất số liệu để đưa vào phân tích tổng hợp được tóm tắt ở Hình 1.

\section{2. Đặc điểm của bộ dũ liệu đưọc trích xuất}

Chi tiết các bước sàng lọc và trích xuất dữ liệu và kết quả thống kê được mô tả ở Hình 1, tổng số từ 113 công bố được chọn từ các cơ sở dữ liệu; sau bước loại bỏ bởi không đáp ứng được các tiêu chí (như đã trình bày ở phần phương pháp), 19 nghiên cứu ca-chứng và 8 nghiên cứu đoàn hệ công bố trong khoảng thời gian từ 2003 đến 2017 được chọn lọc (Bảng 1,2). 


\subsection{Phân tích tương quan giữa tính chất methyl hóa vượt múc vùng promoter gen} GSTP1 với nguy cơ mắc bệnh ung thư vú, trên bộ dũ liệu tù 19 nghiên cúu ca chúng

Bộ dữ liệu thích hợp cho phân tích tổng hợp từ 19 nghiên cứu ca-chứng công bố về tính chất methyl hóa vượt mức vùng promoter gen GSTPl bao gồm 1910 mẫu ung thư vú (472 mẫu máu, 1438 mẫu mô) và 671 mẫu chứng (305 mẫu máu, 366 mẫu mô) (Bảng 1).

Kết quả phân tích (Hình 2) cho thấy tính chất methyl hóa vượt mức vùng promoter gen GSTP1 làm tăng nguy cơ ung thư vú với chỉ số $\mathrm{OR}$ là $10,50(95 \% \mathrm{CI}=4,42$ - 24,94; Mô hình phân tích ảnh hưởng ngẫu nhiên). Mặc dù vậy, tính bất đồng nhất giữa các công trình nghiên cứu là lớn $\left(\mathrm{P}_{\mathrm{H}}<0,0001 ; \mathrm{I}^{2}=77,02 \%\right.$, Hình 2$)$. Tính thiên vị của bộ dữ liệu vì vậy được phân tích và minh họa trên Hình 3. Đồ thị "Funnel plot" (Hình 3) ghi nhận tính thiên vị của bộ dữ liệu từ 19 nghiên cứu ca-chứng này.

3.4. Phân tích tương quan giữa tính chất methyl hóa vượt mức vùng promoter gen GSTP1 với nguy cơ mắc bệnh ung thư vú, trên bộ dũ liệu tù̀ 13 nghiên cúu ca chúng

Từ kết quả phân tích như đã được trình bày ở Hình 2 , một số nghiên cứu cho thấy có mối tương quan thấp làm ảnh hưởng đến độ nhạy của kết quả phân tích. Khi những nghiên cứu này được loại bỏ, chỉ số bất đồng nhất giữa các nghiên cứu trong bộ dữ liệu còn lại, gồm 13 nghiên cứu ca-chứng (1247 mẫu bệnh và 369 mẫu chứng), giảm xuống $\mathrm{I}^{2}=17,39 \%(\mathrm{P}=0,27)$ (Hình 4 ), và mối tương quan giữa tính chất methyl hóa vượt mức vùng promoter gen GSTP1 và nguy cơ mắc ung thư vú tăng $(\mathrm{OR}=13,64 ; 95 \% \mathrm{CI}=8,23-22,60 ; \mathrm{P}<0,001)$ (Hình 4). Thêm vào đó, đồ thị "Funnel plot" (Hình 5 ) ghi nhận tính thiên vị của bộ dữ liệu từ 13 nghiên cứu cachứng này được phân tích.

Các phân hạng được phân tích tiếp theo bao gồm loại mẫu bệnh phẩm được sử dụng cho nghiên cứu, phương pháp phân tích tính chất methyl hóa, chủng tộc, các đặc điểm lâm sàng liên quan đến bệnh ung thư vú như phân độ mô học (histological grade), giai đoạn bệnh (stage), kích thước khối u, sự xuất hiện hạch bạch huyết, sự biểu hiện của thụ thể Her2 và hoạt tính của protein GSTP1.

3.5. Phân tích tương quan giữa tính chất methyl hóa vượt mức vùng promoter gen GSTP1 với nguy cơ mắc bệnh ung thư vú, xét yếu tố loại mẫu bệnh phẩm

Kết quả phân tích (Bảng 3) cho thấy chỉ số OR của tính chất methyl hóa bất thường vùng promoter gen $G S T P 1$, sử dụng mẫu mô trong nghiên cứu, giữa nhóm bệnh nhân ung thư vú so với mô lấy từ người lành hay mô lành nằm kề mô ung thư ở người bệnh là 13,208; tương quan rất chặt chẽ $(95 \% \mathrm{CI}=7,90-22,07 ; \mathrm{P}<0,001$; Mô hình phân tích ảnh hưởng bất biến). Chỉ số tương quan này cũng xấp xỉ chỉ số tương quan khi phân tích chung về tính chất methyl hóa bất thường vùng promoter gen $G S T P 1$ và nguy cơ mắc ung thư vú ở trên (Hình 5 ). Trong khi đó, chỉ số $\mathrm{OR}$ của tính chất methyl hóa bất thường vùng promoter gen $G S T P 1$, sử dụng mẫu máu trong nghiên cứu, giữa nhóm bệnh nhân ung thư vú so với nhóm người lành tăng rất cao, đạt giá trị 27,11 (95\% CI = 1,55-474,99; $\mathrm{P}=0,024)$ (Bảng 3). Như vậy, bên cạnh việc sử dụng mẫu mô, khả năng sử dụng mẫu máu để phân tích tính chất methyl hóa vượt mức vùng promoter gen GSTP1 là rất thuận tiện, từ đó, khả năng áp dụng trong thực tế lâm sàng sẽ cao, đặc biệt khi 
mà sự phát triển của kĩ thuật để từ đó việc sử dụng các loại sinh thiết lỏng (liquid biopsy) ứng dụng trong chẩn đoán, sàng lọc nguy cơ ung thư được dễ dàng hóa.

3.6. Phân tích tương quan giữa tính chất methyl hóa vượt mức vùng promoter gen GSTP1 với nguy cơ mắc bệnh ung thư vú, xét yếu tố phuơng pháp

Kết quả phân tích (Bảng 3) cho thấy chỉ số OR của tính chất methyl hóa vượt mức vùng promoter gen GSTP1, giữa nhóm bệnh nhân ung thư vú so với nhóm người lành hay mô lành nằm kề mô ung thư ở người bệnh, bằng phương pháp MSP đạt giá trị $16,80(95 \% \mathrm{CI}=8,06$ 34,99; $\mathrm{P}<0,001$; Mô hình phân tích ảnh hưởng bất biến). Trong khi đó, chỉ số $\mathrm{OR}$ của tính chất methyl hóa vượt mức vùng promoter gen GSTP1, giữa nhóm bệnh nhân ung thư vú so với nhóm người lành hay mô lành nằm kề mô ung thư ở người bệnh, bằng phương pháp BSP là $6,73(95 \%$ $\mathrm{CI}=2,61-17,33 ; \mathrm{P}<0,001 ;$ Mô hình phân tích ảnh hưởng bất biến), và các phương pháp khác MSP và $B S P$ là 15,72 (95\% $\mathrm{CI}=5,51-44,91 ; \mathrm{P}<0,001$; Mô hình phân tích ảnh hưởng bất biến). Sự tách các phân hạng phương pháp này cũng đã làm tăng chỉ số tương quan OR lên cao hơn so với phân tích chung, và xác định kĩ thuật BSP cũng chính là yếu tố làm giảm chỉ số OR trong các công bố được sử dụng cho phân tích tổng hợp này. Cho đến nay, phương pháp MSP cũng vẫn là phương pháp thông dụng nhất cho phân tích methylation và chỉ số tương quan trong kết quả phân tích cho thấy cao nhất so với việc sử dụng các phương pháp phân tích khác (Bảng 3 ), và đây cũng chính là phương pháp mà chúng tôi đã sử dụng trong thực nghiệm bước đầu của mình (Phuong et al., 2016). Chúng tôi sẽ tiếp tục sử dụng phương pháp MSP trong các thực nghiệm tiếp theo, sử dụng loại mẫu không xâm lấn, đặc biệt là sinh thiết lỏng - một khuynh hướng rất được chú ý phát triển hiện nay trong chẩn đoán ung thư trong các nghiên cứu mang tính thực nghiệm của mình.

\subsection{Phân tích tương quan giữa tính chất methyl hóa vươt mức vùng promoter gen GSTP1 với nguy cơ mắc bệnh ung thư vú, xét yếu tố chủng tộc}

Kết quả phân tích (Bảng 3) cho thấy chỉ số OR của tính chất methyl hóa vượt mức vùng promoter gen GSTP1 của người châu Á giữa nhóm bệnh nhân ung thư vú so với nhóm người lành là $11,06(95 \% \mathrm{CI}=6,36-19,25 ; \mathrm{P}<0,001$; Mô hình phân tích ảnh hưởng bất biến), của người châu Âu là 37,98 (95\% CI = 8,76-164.56; $\mathrm{P}<0,001$; Mô hình phân tích ảnh hưởng bất biến), của người châu Phi là 27,11 $(95 \% \mathrm{CI}=1,55-474,99 ; \mathrm{P}=0,024)$. Qua đó, có thể khẳng định rằng tính chất methyl hóa vượt mức vùng promoter gen GSTP1 là một đặc trưng của bệnh ung thư vú, với các chủng tộc châu Âu và châu Phi, chỉ số tương quan này rất cao và cao hơn so với các chủng tộc châu Á. Khẳng định này là tương đối chính xác với các đại diện công bố được thực hiện từ các chủng tộc châu Á và Âu, tuy nhiên đại diện châu Phi chỉ mới có một nghiên cứu, số liệu vì vậy cần được tiếp tục thu thập và cập nhật thêm trong thời gian tới.

3.8. Phân tích tương quan giữa tính chất methyl hóa vượ mức vùng promoter gen GSTP1 với nguy cơ mắc bệnh ung thư vú, xét yếu tố phân độ mô học

7 nghiên cứu có số liệu về phân độ mô học được sử dụng cho phân tích này. Với kết quả phân tích ghi nhận chỉ số $\mathrm{I}^{2}=59,37 \%(\mathrm{P}=0,02)$, do đó chúng tôi áp dụng mô hình phân tích ảnh hưởng bất biến để phân tích chỉ số $\mathrm{OR}$ của tính chất methyl hóa vượt mức vùng promoter gen GSTPl trong mối tương quan với phân độ mô học (cao hay thấp). Kết quả (Hình 6) cho thấy chỉ số $\mathrm{OR}=1,753(95 \% \mathrm{CI}=1,00-3,06 ; \mathrm{P}=0,009)$, hay nói cách khác, tính chất methyl 
hóa vượt mức vùng promoter gen GSTP1 là một đặc trưng của bệnh ung thư vú, phân độ mô học cao. Chỉ số tương quan OR tăng lên 3,631 $(95 \% \mathrm{CI}=1,95-6,74 ; \mathrm{P}<0,001$; Mô hình phân tích ảnh hưởng bất biến) khi 3 nghiên cứu được loại bỏ (Hình 7).

3.9. Phân tích tương quan giữa tính chất methyl hóa vuột mức vùng promoter gen GSTP1 với nguy cơ mắc bệnh ung thư vú, xét yếu tố giai đoạn bệnh

7 nghiên cứu có số liệu về giai đoạn bệnh sớm (I-II) hay muộn (III-IV) được sử dụng cho phân tích này. Kết quả (Hình 8) cho thấy chỉ số $\mathrm{OR}=2,02(95 \% \mathrm{CI}=1,50$ - 2,73; $\mathrm{P}<0,001$; Mô hình phân tích ảnh hưởng bất biến), hay nói cách khác, tính chất methyl hóa vượt mức vùng promoter gen GSTPI là một đặc trưng của bệnh ung thư vú, giai đoạn muộn của bệnh.

3.10. Phân tích tương quan giữa tính chất methyl hóa vưọt mức vùng promoter gen GSTP1 với nguy cơ mắc bệnh ung thu vú, xét yếu tố kich thuơớc khối u

8 nghiên cứu có số liệu về kích thước khối u lớn hay nhỏ được sử dụng cho phân tích này. Kết quả (Hình 9) cho thấy chỉ số $\mathrm{OR}=2,09(95 \% \mathrm{CI}=1,04-4,22 ; \mathrm{P}=0,005$; Mô hình phân tích ảnh hưởng ngẫu nhiên). Chỉ số tương quan này tăng lên khi 2 nghiên cứu được loại bỏ (Hình 10), $\mathrm{OR}=3,01(95 \% \mathrm{CI}=1,87-4,85 ; \mathrm{P}<0,001$; Mô hình phân tích ảnh hưởng bất biến), hay nói cách khác, tính chất methyl hóa vượt mức vùng promoter gen GSTP1 là một đặc trưng của bệnh ung thư vú, kích thước khối u lớn.

3.11. Phân tích tương quan giữa tính chất methyl hóa vươt mức vùng promoter gen GSTP1 với nguy cơ mắc bệnh ung thu vú, xét yếu tố có hay khồng sụ xuất hiện của hạch bạch huyết

11 nghiên cứu có số liệu về sự xuất hiện của hạch bạch huyết ở bệnh nhân được sử dụng cho phân tích này. Kết quả (Hình 11) cho thấy chỉ số $\mathrm{OR}=2,29(95 \% \mathrm{CI}=1,70-3,07 ; \mathrm{P}<$ 0,001; Mô hình phân tích ảnh hưởng bất biến), hay nói cách khác, tính chất methyl hóa vượt mức vùng promoter gen GSTP1 là một đặc trưng của bệnh ung thư vú, bệnh nhân có sự xuất hiện của hạch bạch huyết.

3.12. Phân tích tương quan giữa tính chất methyl hóa vuột mức vùng promoter gen GSTP1 với nguy cơ mắc bệnh ung thư vú, xét yếu tố có hay không sụ biểu hiện của Her2

10 nghiên cứu có số liệu về sự biểu hiện của Her2 ở bệnh nhân được sử dụng cho phân tích này. Kết quả (Hình 12) cho thấy chỉ số $\mathrm{OR}=2,50(95 \% \mathrm{CI}=1,77-3,52 ; \mathrm{P}<0,001$; Mô hình phân tích ảnh hưởng bất biến), hay nói cách khác, tính chất methyl hóa vượt mức vùng promoter gen GSTP1 là một đặc trưng của bệnh ung thư vú, bệnh nhân có sự biểu hiện của Her2.

3.13. Phân tích tương quan giữa tính chất methyl hóa vuột mức vùng promoter gen GSTP1 với nguy cơ mắc bệnh ung thư vú, xét yếu tố chức năng của protein GSTP1

5 nghiên cứu có số liệu về hoạt động chức năng của protein GSTP1 ở bệnh nhân được sử dụng cho phân tích này. Kết quả (Hình 13) cho thấy chỉ số $\mathrm{OR}=18,30(95 \% \mathrm{CI}=4,09$ 81,91; P < 0,001; Mô hình phân tích ảnh hưởng bất biến), hay nói cách khác, tính chất methyl hóa vượt mức vùng promoter gen GSTPI là một đặc trưng của bệnh ung thư vú, ở những bệnh nhân này, chức năng của protein GSTP1 giảm rõ rệt. 
Methyl hóa trên gen là một cơ chế epigenetic có tính thuận nghịch; nghĩa là methyl hóa có thể sinh ra và mất đi trong quá trình sống. Gen GSTPl lại là gen có chức năng khử độc cho tế bào. Việc gen có thể bị methyl hóa, làm ảnh hưởng đến hoạt động chức năng, gen không được hoặc giảm phiên mã/dịch mã, từ đó, chức năng khử độc cho tế bào có thể giảm. Như vậy, việc áp dụng thử nghiệm phương thức điều trị bằng các thuốc epi-drugs, nhằm khử methyl hóa gen; có thể chọn gen GSTP1 như một gen tiềm năng để thử nghiệm. Điều này được củng cố thêm qua kết quả phân tích tổng hợp này, nhất là đối với bệnh nhân ở thể nặng. Các bệnh nhân này (có kích thước u lớn, giai đoạn bệnh muộn, phân độ mô học cao, có sự xuất hiện hạch bạch huyết và Her2) là những lựa chọn phù hợp cho thử nghiệm epi-drugs khi GSTP1 bị methyl hóa vượt mức ở các đảo $\mathrm{CpG}$ thuộc vùng promoter của gen.

\section{Kết luận}

Kết quả phân tích tổng hợp của chúng tôi vừa trình bày trên đây ghi nhận tính chất methyl hóa vượt mức vùng promoter gen GSTP1 đã làm tăng nguy cơ mắc bệnh ung thư vú lên hơn 10 lần $(\mathrm{OR}=10,497 ; 95 \% \mathrm{CI}=4,42-24,94 ; \mathrm{P}<0,0001$; Mô hình phân tích ảnh hưởng ngẫu nhiên). Mối tương quan này tăng khi áp dụng mô hình phân tích ảnh hưởng bất biến với bộ dữ liệu được chọn lọc, chỉ số nguy cơ lúc này là tăng 13,642 lần $(95 \% \mathrm{CI}=8,23$ - 22,60; $\mathrm{P}$ $<0,001$; Mô hình phân tích ảnh hưởng bất biến). Khi tách các phân hạng, chỉ số tương quan này đều tăng; khẳng định tính chất methyl hóa vượt mức vùng promoter gen GSTP1 xuất hiện ở cả mẫu mô lẫn mẫu máu, tính chất methyl hóa vượt mức này nên được xác định bằng phương pháp Methylation Specific PCR và các phương pháp khác như Pyrosequencing, MS-MLPA, Methylight và QMSP, so với Bisulfite methylation specific PCR. Methyl hóa vượt mức vùng promoter gen GSTP1 xuất hiện cao ở các chủng tộc châu Âu so với châu Á. Xét sự tương quan giữa tính chất methyl hóa vượt mức vùng promoter gen GSTPl với các phân hạng phản ánh đặc điểm lâm sàng của bệnh ung thư vú, kết quả phân tích tổng hợp của chúng tôi khẳng định tính chất methyl hóa vượt mức vùng promoter gen GSTP 1 là một đặc trưng của bệnh nhân ung thư vú có phân độ mô học cao, giai đoạn bệnh muộn, kích thước khối u lớn bên cạnh việc có sự xuất hiện hạch bạch huyết và biểu hiện của thụ thể Her2 ở bệnh nhân. Sự methyl hóa vượt mức vùng promoter gen GSTP1 cũng chính là nguyên nhân làm giảm hàm lượng và chức năng protein GSTP1. Các đặc trưng này gợi ý việc có thể thử nghiệm phương thức điều trị cho các bệnh nhân ung thư vú giai đoạn muộn của bệnh bằng các epi-drugs nhằm giải methyl hóa cho các bệnh nhân này, tăng cơ hội lui bệnh cho các bệnh nhân. 


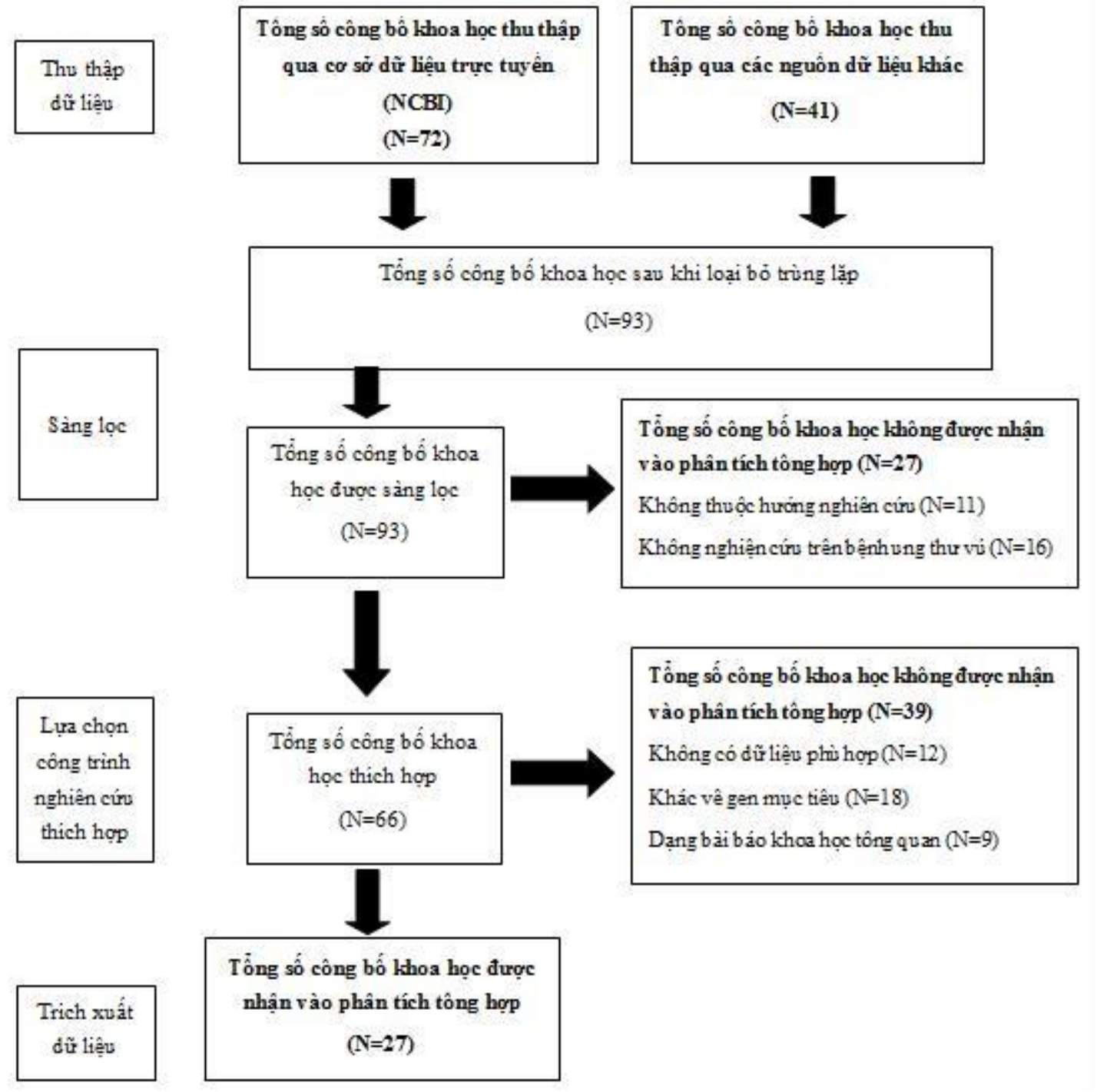

Hình 1. Sơ đồ mô tả quy trình chọn lọc công trình nghiên cứu vào bộ dữ liệu phân tích tổng hợp 


\section{Bảng 1}

Đặc điểm của bộ dữ liệu 19 nghiên cứu ca-chứng về sự methyl hóa vượt mức vùng promoter gen GSTP1

\begin{tabular}{|c|c|c|c|c|c|c|c|c|c|c|c|}
\hline \multirow[b]{2}{*}{$\begin{array}{l}\text { Công trình } \\
\text { nghiên cứu }\end{array}$} & \multirow[b]{2}{*}{$\begin{array}{c}\text { Quốc } \\
\text { gia }\end{array}$} & \multirow[b]{2}{*}{$\begin{array}{l}\text { Chủng } \\
\text { tộc }\end{array}$} & \multirow[b]{2}{*}{ Phương pháp } & \multirow[b]{2}{*}{$\begin{array}{l}\text { Loại } \\
\text { mâ̂u }\end{array}$} & \multicolumn{3}{|c|}{ Mẫu bệnh ung thư vú } & \multicolumn{3}{|c|}{ Mẫu chứng } & \multirow[b]{2}{*}{$\begin{array}{c}\text { Đặc điểm mấu } \\
\text { chứng }\end{array}$} \\
\hline & & & & & $\begin{array}{c}\text { Mẫu } \\
\text { methyl } \\
\text { hóa }\end{array}$ & $\begin{array}{c}\text { Mẫu } \\
\text { không } \\
\text { bị } \\
\text { methyl } \\
\text { hóa }\end{array}$ & $\begin{array}{l}\text { Tổng } \\
\text { mấu }\end{array}$ & $\begin{array}{c}\text { Mẫu } \\
\text { methyl } \\
\text { hóa }\end{array}$ & $\begin{array}{c}\text { Mẫu } \\
\text { không } \\
\text { bị } \\
\text { methyl } \\
\text { hóa }\end{array}$ & $\begin{array}{l}\text { Tổng } \\
\text { mấu }\end{array}$ & \\
\hline $\begin{array}{l}\text { Bhat và cộng sự } \\
\text { (2017) }\end{array}$ & Ấn Độ & $\begin{array}{c}\text { Châu } \\
\text { Á }\end{array}$ & MSP & Mô & 19 & 32 & 51 & 6 & 45 & 51 & Mô lân cận \\
\hline $\begin{array}{l}\text { Wu và cộng sự } \\
\text { (2016) }\end{array}$ & $\begin{array}{l}\text { Trung } \\
\text { Quốc }\end{array}$ & $\begin{array}{c}\text { Châu } \\
\text { Á }\end{array}$ & MSP & Mô & 22 & 48 & 70 & 0 & 20 & 20 & $\begin{array}{l}\text { Mẫu của người } \\
\text { lành }\end{array}$ \\
\hline $\begin{array}{l}\text { Shakeri, } \\
\text { Gharesouran, } \\
\text { Fakhrjou, } \\
\text { Esfahani, và } \\
\text { Ardebili (2016) }\end{array}$ & Iran & $\begin{array}{c}\text { Châu } \\
\text { Á }\end{array}$ & MS-MLPA & Mô & 27 & 48 & 75 & 0 & 10 & 10 & $\begin{array}{c}\text { Mẫu của người } \\
\text { lành }\end{array}$ \\
\hline Thao (2015) & $\begin{array}{l}\text { Việt } \\
\text { Nam }\end{array}$ & $\begin{array}{c}\text { Châu } \\
\text { Á }\end{array}$ & MSP & Mô & 41 & 54 & 95 & 0 & 20 & 20 & $\begin{array}{l}\text { Mẫu của người } \\
\text { lành }\end{array}$ \\
\hline $\begin{array}{l}\text { Hafez và cộng } \\
\text { sự (2015) }\end{array}$ & $\begin{array}{l}\text { Ả Rập } \\
\text { Saudi }\end{array}$ & $\begin{array}{c}\text { Châu } \\
\text { Á }\end{array}$ & MSP & Mô & 89 & 91 & 180 & 0 & 20 & 20 & $\begin{array}{l}\text { Mẫu của người } \\
\text { lành }\end{array}$ \\
\hline $\begin{array}{l}\text { Jung và cộng sự } \\
\text { (2013) }\end{array}$ & $\begin{array}{l}\text { Hàn } \\
\text { quốc }\end{array}$ & Châu & MS-MLPA & Mô & 10 & 50 & 60 & 2 & 58 & 60 & Mô lân cận \\
\hline $\begin{array}{l}\text { Klajic và cộng } \\
\text { sự (2013) }\end{array}$ & Na uy & $\begin{array}{c}\text { Châu } \\
\hat{A} u\end{array}$ & Pyrosequencing & Mô & 142 & 77 & 219 & 0 & 6 & 6 & $\begin{array}{c}\text { Mẫu mô của } \\
\text { người lành }\end{array}$ \\
\hline $\begin{array}{l}\text { Sturgeon và } \\
\text { cộng sự (2012) }\end{array}$ & Mỹ & $\begin{array}{l}\text { Châu } \\
\text { Mỹ }\end{array}$ & Pyrosequencing & Máu & 233 & 71 & 304 & 186 & 48 & 234 & $\begin{array}{l}\text { Mẫu của người } \\
\text { lành }\end{array}$ \\
\hline $\begin{array}{l}\text { Yamamoto và } \\
\text { cộng sự (2012) }\end{array}$ & $\begin{array}{l}\text { Nhật } \\
\text { bản }\end{array}$ & $\begin{array}{c}\text { Châu } \\
\text { Á }\end{array}$ & MSP & Mô & 45 & 49 & 94 & 1 & 52 & 53 & $\begin{array}{l}\text { Mẫu của người } \\
\text { lành }\end{array}$ \\
\hline
\end{tabular}




\begin{tabular}{|c|c|c|c|c|c|c|c|c|c|c|c|}
\hline \multirow[b]{2}{*}{$\begin{array}{l}\text { Công trình } \\
\text { nghiên cứu }\end{array}$} & \multirow[b]{2}{*}{$\begin{array}{l}\text { Quốc } \\
\text { gia }\end{array}$} & \multirow[b]{2}{*}{$\begin{array}{l}\text { Chủng } \\
\text { tộc }\end{array}$} & \multirow[b]{2}{*}{ Phương pháp } & \multirow[b]{2}{*}{$\begin{array}{l}\text { Loại } \\
\text { mâ̂u }\end{array}$} & \multicolumn{3}{|c|}{ Mẫu bệnh ung thư vú } & \multicolumn{3}{|c|}{ Mẫu chứng } & \multirow[b]{2}{*}{$\begin{array}{c}\text { Đặc điểm mẫu } \\
\text { chứng }\end{array}$} \\
\hline & & & & & $\begin{array}{c}\text { Mẫu } \\
\text { methyl } \\
\text { hóa }\end{array}$ & $\begin{array}{c}\text { Mẫu } \\
\text { không } \\
\text { bị } \\
\text { methyl } \\
\text { hóa }\end{array}$ & $\begin{array}{l}\text { Tổng } \\
\text { mấu }\end{array}$ & $\begin{array}{c}\text { Mẫu } \\
\text { methyl } \\
\text { hóa }\end{array}$ & $\begin{array}{c}\text { Mẫu } \\
\text { không } \\
\text { bị } \\
\text { methyl } \\
\text { hóa }\end{array}$ & $\begin{array}{l}\text { Tổng } \\
\text { mấu }\end{array}$ & \\
\hline $\begin{array}{l}\text { Shargh, } \\
\text { Hosseini, và } \\
\text { Sakizli (2011) }\end{array}$ & $\begin{array}{l}\text { Ả Rập } \\
\text { Saudi }\end{array}$ & $\begin{array}{c}\text { Châu } \\
\text { Á }\end{array}$ & BSP & Mô & 19 & 27 & 46 & 6 & 41 & 47 & Mô lân cận \\
\hline $\begin{array}{l}\text { Park và cộng sự } \\
\text { (2010) }\end{array}$ & $\begin{array}{l}\text { Hàn } \\
\text { quốc }\end{array}$ & $\begin{array}{c}\text { Châu } \\
\text { Á }\end{array}$ & Methylight & Mô & 26 & 79 & 115 & 0 & 30 & 30 & $\begin{array}{l}\text { Mẫu của người } \\
\text { lành }\end{array}$ \\
\hline $\begin{array}{l}\text { Matuschek và } \\
\text { cộng sự (2010) }\end{array}$ & Đức & $\begin{array}{c}\text { Châu } \\
\hat{A} u\end{array}$ & Methylight & Máu & 15 & 70 & 85 & 1 & 22 & 23 & $\begin{array}{l}\text { Mẫu của người } \\
\text { lành }\end{array}$ \\
\hline $\begin{array}{l}\text { Dejeux và cộng } \\
\text { sự (2010) }\end{array}$ & $\begin{array}{l}\text { Thưy } \\
\text { Điền }\end{array}$ & $\begin{array}{c}\text { Châu } \\
\hat{A} u\end{array}$ & Pyrosequencing & Mô & 135 & 28 & 163 & 0 & 6 & 6 & $\begin{array}{l}\text { Mẫu của người } \\
\text { lành }\end{array}$ \\
\hline $\begin{array}{l}\text { Rønneberg và } \\
\text { cộng sự (2008) }\end{array}$ & Ý & $\begin{array}{l}\text { Châu } \\
\hat{A} u\end{array}$ & BSP & Mô & 57 & 24 & 80 & 0 & 6 & 6 & $\begin{array}{l}\text { Mẫu của người } \\
\text { lành }\end{array}$ \\
\hline Lee (2007) & $\begin{array}{l}\text { Hàn } \\
\text { quốc }\end{array}$ & $\begin{array}{c}\text { Châu } \\
\text { Á }\end{array}$ & Nested MSP & Mô & 36 & 73 & 109 & 0 & 15 & 15 & $\begin{array}{l}\text { Mẫu của người } \\
\text { lành }\end{array}$ \\
\hline $\begin{array}{l}\text { Hoque và cộng } \\
\text { sự (2006) }\end{array}$ & Senegal & $\begin{array}{l}\text { Châu } \\
\text { Phi }\end{array}$ & QMSP & plasma & 12 & 35 & 47 & 0 & 38 & 38 & $\begin{array}{l}\text { Mẫu của người } \\
\text { lành }\end{array}$ \\
\hline $\begin{array}{l}\text { Parrella và cộng } \\
\text { sự (2003) }\end{array}$ & Ý & $\begin{array}{c}\text { Châu } \\
\hat{A} u\end{array}$ & MSP & Mô & 7 & 47 & 54 & 0 & 10 & 10 & $\begin{array}{l}\text { Mẫu của người } \\
\text { lành }\end{array}$ \\
\hline $\begin{array}{l}\text { Jerónimo và } \\
\text { cộng sự (2003) }\end{array}$ & $\begin{array}{c}\text { Bồ đào } \\
\text { nha }\end{array}$ & $\begin{array}{c}\text { Châu } \\
\hat{A} u\end{array}$ & MSP & Mô & 18 & 9 & 27 & 0 & 12 & 12 & $\begin{array}{l}\text { Mẫu của người } \\
\text { lành }\end{array}$ \\
\hline $\begin{array}{l}\text { Müller và cộng } \\
\text { sự (2003) }\end{array}$ & Úc & $\begin{array}{l}\text { Châu } \\
\text { Úc }\end{array}$ & Methylight & Serum & 9 & 27 & 36 & 1 & 9 & 10 & $\begin{array}{l}\text { Mẫu của người } \\
\text { lành }\end{array}$ \\
\hline
\end{tabular}

Chú thích: tổng mẫu bệnh: 1910 mẫu (472 mẫu máu và 1438 mẫu mô); tổng mẫu chứng: 671 mẫu (305 mẫu máu và 366 mẫu mô)

Nguồn: Kết quả phân tích dữ liệu của nhóm nghiên cứu 


\section{Bảng 2}

Đặc điểm của bộ dữ liệu 8 nghiên cứu đoàn hệ về sự methyl hóa vượt mức vùng promoter gen GSTP1

\begin{tabular}{|c|c|c|c|c|c|c|c|c|}
\hline \multirow{2}{*}{$\begin{array}{l}\text { Công trình } \\
\text { nghiên cứu }\end{array}$} & \multirow[b]{2}{*}{ Quốc gia } & \multirow{2}{*}{$\begin{array}{c}\text { Chủng } \\
\text { tộc }\end{array}$} & \multirow{2}{*}{$\begin{array}{c}\text { Phương } \\
\text { pháp }\end{array}$} & \multirow{2}{*}{$\begin{array}{l}\text { Loại } \\
\text { mâ̂u }\end{array}$} & \multicolumn{3}{|c|}{ Mẫu bệnh ung thư vú } & \multirow[b]{2}{*}{ Đặc điểm mẫu chứng } \\
\hline & & & & & $\begin{array}{c}\text { Mẫu } \\
\text { methyl hóa }\end{array}$ & $\begin{array}{l}\text { Mẫu không bị } \\
\text { methyl hóa }\end{array}$ & $\begin{array}{l}\text { Tổng } \\
\text { mẫu }\end{array}$ & \\
\hline $\begin{array}{l}\text { Saxena và cộng } \\
\text { sự (2012) }\end{array}$ & Ân Độ & Châu Á & MSP & Tissue & 74 & 141 & 215 & Mô lân cận \\
\hline $\begin{array}{l}\text { Pongtheerat, } \\
\text { Pakdeethai, } \\
\text { Purisa, } \\
\text { Chariyalertsak, } \\
\text { và Petmitr } \\
(2011)\end{array}$ & Thái Lan & Châu Á & MSP & Tissue & 11 & 30 & 41 & Mẫu của người lành \\
\hline $\begin{array}{l}\text { Sharma và cộng } \\
\text { sự (2009) }\end{array}$ & Ân Độ & Châu Á & MSP & tissue & 25 & 86 & 101 & Mẫu của người lành \\
\hline $\begin{array}{l}\text { Lasabova và } \\
\text { cộng sự (2009) }\end{array}$ & Slovakia & $\begin{array}{l}\text { Châu } \\
\hat{A} u\end{array}$ & nested-MSP & tissue & 11 & 34 & 45 & Mẫu của người lành \\
\hline $\begin{array}{l}\text { Sunami và cộng } \\
\text { sự (2008) }\end{array}$ & Mỹ & $\begin{array}{l}\text { Châu } \\
\text { Mỹ }\end{array}$ & MSP & Tissue & 23 & 107 & 130 & Mô lân cận \\
\hline $\begin{array}{l}\text { Hoque và cộng } \\
\text { sự (2006) }\end{array}$ & Senegal & $\begin{array}{l}\text { Châu } \\
\text { Phi }\end{array}$ & QMSP & Tissue & 11 & 68 & 79 & Mẫu của người lành \\
\hline $\begin{array}{l}\text { Arai và cộng sự } \\
\text { (2006) }\end{array}$ & Nhật bản & Châu Á & MSP & tissue & 24 & 150 & 174 & Mẫu của người lành \\
\hline $\begin{array}{l}\text { Shinozaki và } \\
\text { cộng sự (2005) }\end{array}$ & Mỹ & $\begin{array}{l}\text { Châu } \\
\text { Mỹ }\end{array}$ & MSP & Tissue & 32 & 119 & 151 & Mô lân cận \\
\hline
\end{tabular}

Chú thích: Hoque và cộng sự (2006) thuộc dạng nghiên cứu cắt ngang.

Nguồn: Kết quả phân tích dữ liệu của nhóm nghiên cứu 


\section{Bảng 3}

Tính chất methyl hóa vượt mức vùng promoter gen GSTPl trên bộ dữ liệu 13 nghiên cứu ca-chứng về bệnh ung thư vú

\begin{tabular}{|c|c|c|c|c|c|c|c|}
\hline \multicolumn{5}{|c|}{ Phân tích ảnh hưởng } & \multicolumn{3}{|c|}{ Phân tích tính bất đồng nhất } \\
\hline Chỉ số & $\mathbf{N}$ & OR $(95 \% \mathrm{CI})$ & $\mathbf{Z}$ & P-value & Model & $\mathbf{P h}$ & $\mathbf{I}^{2}(\%)$ \\
\hline Tổng số & 13 & $13,642[8,23-22,60]$ & 10,14 & $<0,001$ & $\mathrm{~F}$ & 0,27 & 17,39 \\
\hline \multicolumn{8}{|l|}{ Loại mẫu } \\
\hline Mẫu mô & 12 & $13,208[7,90-22,07]$ & 9,86 & $<0,001$ & $\mathrm{~F}$ & 0,23 & 21,45 \\
\hline Mẫu máu & 1 & $27,11[1,55-474,99]$ & 2,25 & 0,024 & NA & NA & NA \\
\hline \multicolumn{8}{|c|}{ Phương pháp } \\
\hline MSP & 6 & $16,80[8,06-34,99]$ & 7,53 & $<0,001$ & $\mathrm{~F}$ & 0,12 & 41,54 \\
\hline BSP & 2 & $6,73[2,61-17,33]$ & 3,95 & $<0,001$ & $\mathrm{~F}$ & 0,22 & 32,99 \\
\hline Khác* & 5 & $15,72[5,51-44,91]$ & 5,15 & $<0,001$ & $\mathrm{~F}$ & 0,62 & 0,00 \\
\hline \multicolumn{8}{|l|}{ Ethnicity } \\
\hline Châu Á & 8 & $11,06[6,36-19,25]$ & 8,50 & $<0,001$ & $\mathrm{~F}$ & 0,20 & 28,19 \\
\hline Châu Âu & 4 & $37,98[8,76-164,56]$ & 4,86 & $<0,001$ & $\mathrm{~F}$ & 0,96 & 0,00 \\
\hline Châu Phi & 1 & $27,11[1,55-474,99]$ & 2,25 & 0,024 & NA & NA & NA \\
\hline
\end{tabular}

Khác*: Pyrosequencing, MS-MLPA, Methylight và QMSP.

Nguồn: Kết quả phân tích dữ liệu của nhóm nghiên cứu 


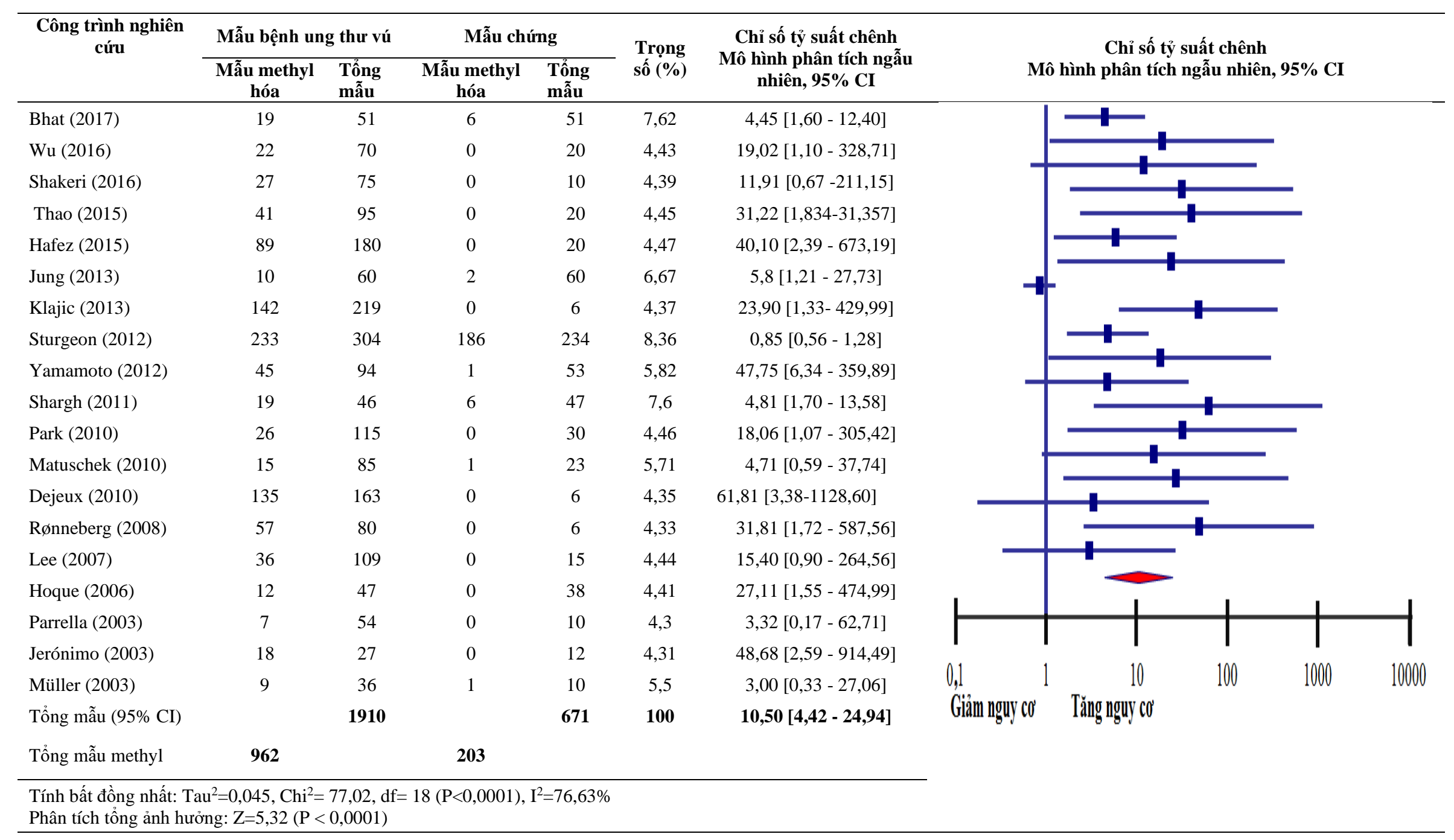

Hình 2. Kết quả phân tích tính chất methyl hóa vượt mức vùng promoter gen GSTP1 trên bộ dữ liệu 19 nghiên cứu ca-chứng về bệnh ung thư vú 


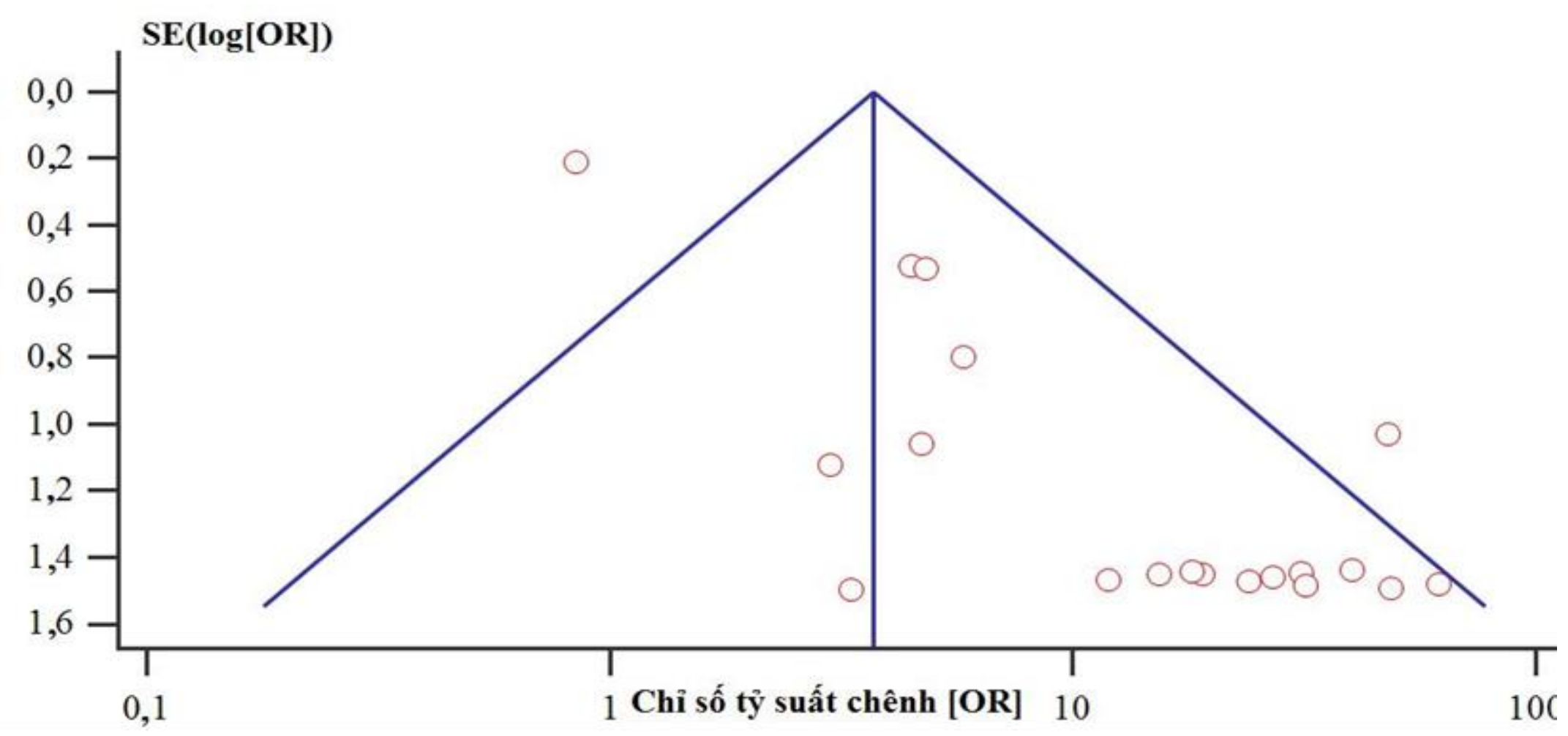

Hình 3. Đồ thị "Funnel plot” đánh giá tính thiên vị trên bộ dữ liệu 19 công trình nghiên cứu ca-chứng về bệnh ung thư vú 


\begin{tabular}{|c|c|c|c|c|c|c|c|}
\hline \multirow[t]{2}{*}{$\begin{array}{l}\text { Công trình } \\
\text { nghiên cứu }\end{array}$} & \multicolumn{2}{|c|}{$\begin{array}{l}\text { Mẫu bệnh ung } \\
\text { thư vú }\end{array}$} & \multicolumn{2}{|c|}{ Mẫu chứng } & \multirow[b]{2}{*}{$\begin{array}{l}\text { Trọng } \\
\text { số (\%) }\end{array}$} & \multirow{2}{*}{$\begin{array}{l}\text { Chỉ số tỷ suất chênh } \\
\text { Mô hình phân tích bất } \\
\text { biến, } 95 \% \text { CI }\end{array}$} & \multirow{2}{*}{$\begin{array}{l}\text { Chỉ số tỷ suất chênh } \\
\text { Mô hình phân tích bất biến, } 95 \% \text { CI }\end{array}$} \\
\hline & $\begin{array}{l}\text { Mẫu } \\
\text { methyl } \\
\text { hóa }\end{array}$ & $\begin{array}{l}\text { Tổng } \\
\text { mấu }\end{array}$ & $\begin{array}{l}\text { Mẫu } \\
\text { methyl } \\
\text { hóa }\end{array}$ & $\begin{array}{l}\text { Tổng } \\
\text { mấu }\end{array}$ & & & \\
\hline Bhat (2017) & 19 & 51 & 6 & 51 & 26,31 & $4,45[1,60-12,40]$ & \\
\hline $\mathrm{Wu}(2016)$ & 22 & 70 & 0 & 20 & 3,39 & $19,02[1,10-328,71]$ & \\
\hline Thao (2015) & 41 & 95 & 0 & 20 & 3,43 & $31,22[1,834-531,357]$ & \\
\hline Hafez (2015) & 89 & 180 & 0 & 20 & 3,47 & $40,10[2,39-673,19]$ & \\
\hline Jung (2013) & 10 & 60 & 2 & 60 & 11,26 & $5,8[1,21-27,73]$ & \\
\hline Klajic (2013) & 142 & 219 & 0 & 6 & 3,3 & $23,90[1,33-429,99]$ & \\
\hline $\begin{array}{l}\text { Yamamoto } \\
(2012)\end{array}$ & 45 & 94 & 1 & 53 & 6,76 & $47,75[6,34-359,89]$ & \\
\hline Shargh (2011) & 19 & 46 & 6 & 47 & 25,56 & $4,81[1,70-13,58]$ & \\
\hline Park (2010) & 26 & 115 & 0 & 30 & 3,45 & $18,06[1,07-305,42]$ & \\
\hline Dejeux (2010) & 135 & 163 & 0 & 6 & 3,27 & $61,81[3,38-1128,60]$ & \\
\hline $\begin{array}{l}\text { Rønneberg } \\
\text { (2008) }\end{array}$ & 57 & 80 & 0 & 6 & 3,24 & $31,81[1,72-587,56]$ & \\
\hline Hoque (2006) & 12 & 47 & 0 & 38 & 3,36 & $27,11[1,55-474,99]$ & \\
\hline $\begin{array}{l}\text { Jerónimo } \\
(2003)\end{array}$ & 18 & 27 & 0 & 12 & 3,2 & $48,68[2,59-914,49]$ & $t$ \\
\hline $\begin{array}{l}\text { Tổng mẫu }(95 \% \\
\text { CI) }\end{array}$ & & 1247 & & 369 & 100 & $13,64[8,23-22,60]$ & 1000 \\
\hline $\begin{array}{l}\text { Tổng mẫu } \\
\text { methyl }\end{array}$ & 635 & & 15 & & & & Giảm nğuy cơ Tănğ nğuy cơ \\
\hline Tính bất đồng nh & $\mathrm{Chi}^{2}=1$ & $3, \mathrm{df}=$ & $12(\mathrm{P}=0,2$ & $\mathrm{I}^{2}=1$ & $39 \%$ & & \\
\hline Phân tích tổng ải & hưởng: : & 10,14 & $<0,001)$ & & & & \\
\hline
\end{tabular}

Hình 4. Kết quả phân tích tính chất methyl hóa vượt mức vùng promoter gen GSTPl trên bộ dữ liệu 13 nghiên cứu ca-chứng về bệnh ung thư vú 


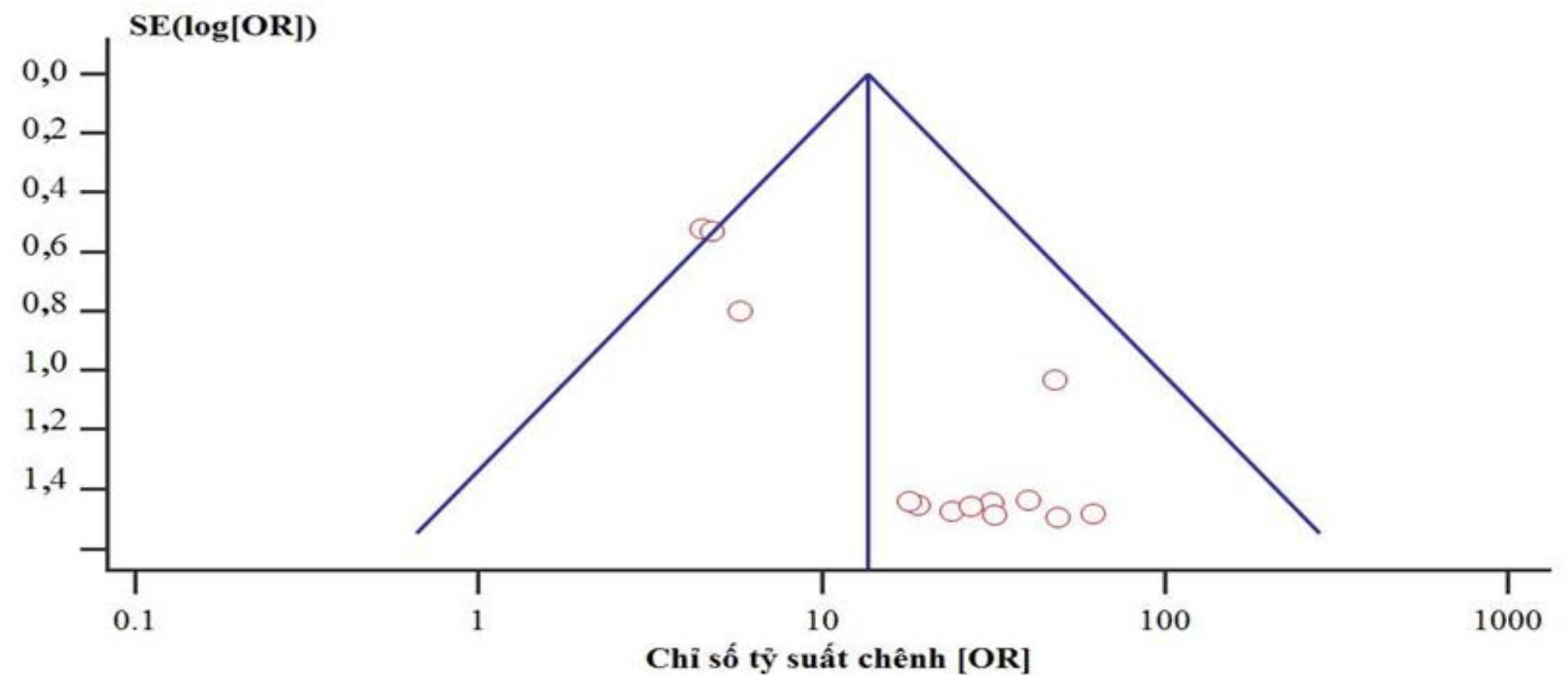

Hình 5. Đồ thị "Funnel plot" đánh giá tính thiên vị trên bộ dữ liệu 19 công trình nghiên cứu ca-chứng về bệnh ung thư vú 


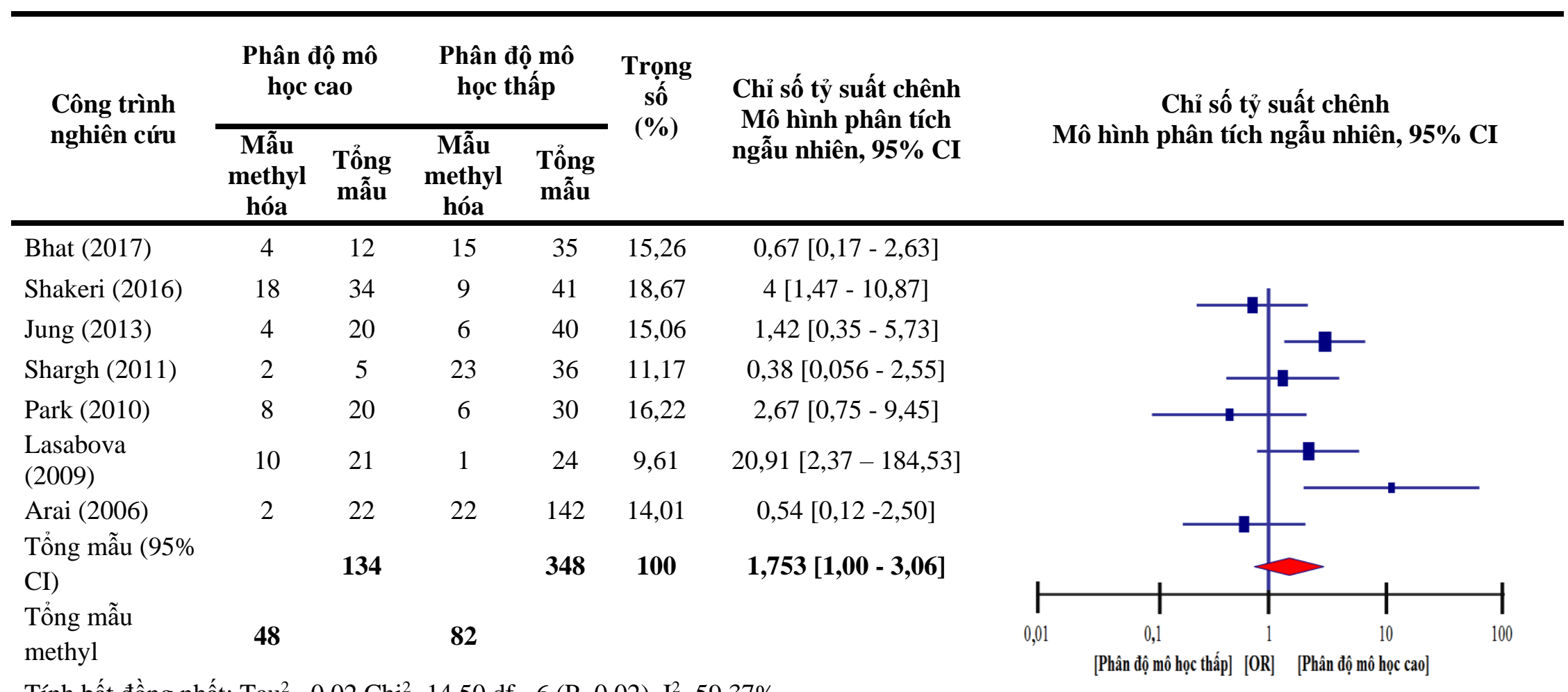

Tính bất đồng nhất: $\mathrm{Tau}^{2}=0,02 \mathrm{Chi}^{2}=14,50 \mathrm{df}=6(\mathrm{P}=0,02), \mathrm{I}^{2}=59,37 \%$

Phân tích tổng ảnh hưởng: $\mathrm{Z}=2,60(\mathrm{P}=0,009)$

Hình 6. Kết quả phân tích tính chất methyl hóa vượt mức vùng promoter gen GSTP1 trên bộ dữ liệu 7 nghiên cứu về bệnh ung thư vú, xét yếu tố phân độ mô học (cao và thấp) 


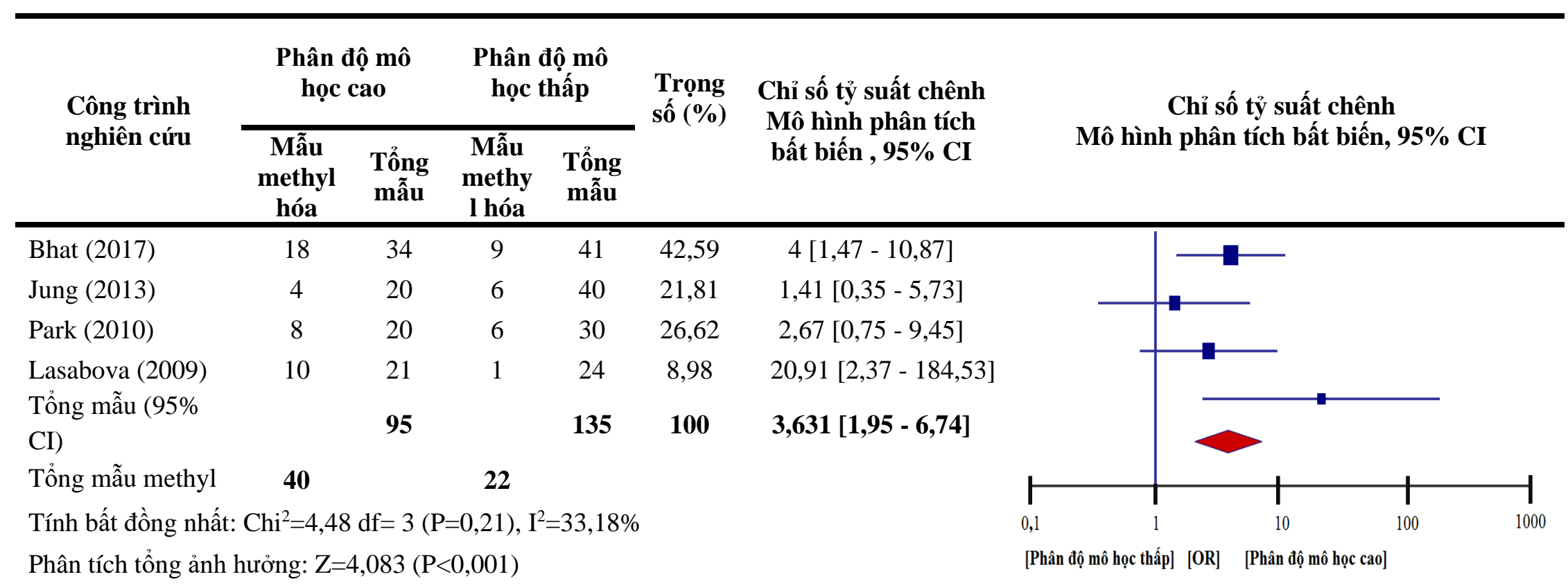

Hình 7. Kết quả phân tích tính chất methyl hóa vượt mức vùng promoter gen GSTP1 trên bộ dữ liệu 4 nghiên cứu về bệnh ung thư vú, xét yếu tố phân độ mô học (cao và thấp) 


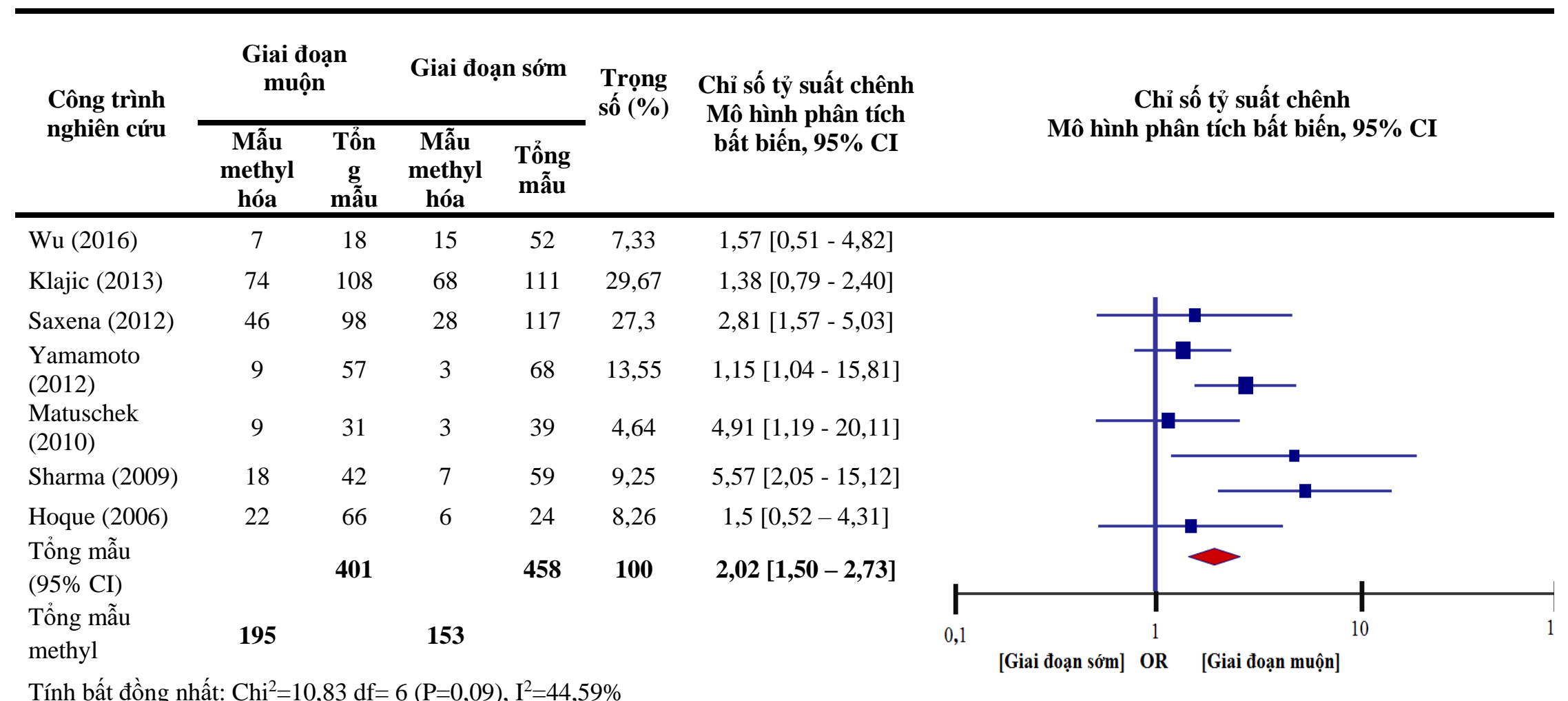

Phân tích tổng ảnh hưởng: $\mathrm{Z}=4,62(\mathrm{P}<0,001)$

Hình 8. Kết quả phân tích tính chất methyl hóa vượt mức vùng promoter gen GSTP1 trên bộ dữ liệu 7 nghiên cứu về bệnh ung thư vú, xét yếu tố giai đoạn bệnh (sớm hay muộn) 


\begin{tabular}{|c|c|c|c|c|c|c|c|}
\hline \multirow{2}{*}{$\begin{array}{l}\text { Công trình } \\
\text { nghiên cứu }\end{array}$} & \multicolumn{2}{|c|}{$\begin{array}{l}\text { Kích thước } \\
\text { khối u lớn }\end{array}$} & \multicolumn{2}{|c|}{$\begin{array}{l}\text { Kích thước } \\
\text { khối u nhỏ }\end{array}$} & \multirow{2}{*}{$\begin{array}{l}\text { Trọng } \\
\text { số }(\%)\end{array}$} & \multirow{2}{*}{$\begin{array}{c}\text { Chỉ số tỷ suất } \\
\text { chênh } \\
\text { Mô hình phân tích } \\
\text { ngấu nhiên, } 95 \% \\
\text { CI }\end{array}$} & \multirow{2}{*}{$\begin{array}{c}\text { Chỉ số tỷ suất chênh } \\
\text { Mô hình phân tích ngấu nhiên, } 95 \% \text { CI }\end{array}$} \\
\hline & $\begin{array}{c}\text { Mẫu } \\
\text { methyl } \\
\text { hóa }\end{array}$ & $\begin{array}{l}\text { Tổng } \\
\text { mẫu }\end{array}$ & $\begin{array}{c}\text { Mẫu } \\
\text { methy } \\
1 \text { hóa }\end{array}$ & $\begin{array}{l}\text { Tổng } \\
\text { mấu }\end{array}$ & & & \\
\hline Wu (2016) & 16 & 52 & 6 & 18 & 12,63 & $0,89[0,83-2,79]$ & \\
\hline Shakeri (2016) & 15 & 39 & 12 & 36 & 14,12 & $1,25[0,48-3,22]$ & \\
\hline Hafez (2015) & 40 & 88 & 49 & 92 & 16,78 & $0,73[0,40-1,31]$ & \\
\hline $\begin{array}{l}\text { Pongtheerat } \\
\text { (2011) }\end{array}$ & 3 & 12 & 6 & 28 & 9,63 & $1,22[0,25-5,98]$ & \\
\hline $\begin{array}{l}\text { Matuschek } \\
(2010)\end{array}$ & 6 & 11 & 6 & 57 & 10,44 & $10,2[2,37-43,81]$ & \\
\hline Sharma (2009) & 18 & 44 & 7 & 57 & 13,77 & $2,5[0,61-10,19]$ & \\
\hline $\begin{array}{l}\text { Lasabova } \\
\text { (2009) }\end{array}$ & 7 & 21 & 4 & 24 & 10,78 & $5,13[1,46-17,95]$ & \\
\hline Arai (2006) & 21 & 107 & 3 & 66 & 11,84 & $5,13[1,46-17,95]$ & \\
\hline $\begin{array}{l}\text { Tổng mẫu } \\
(95 \% \mathrm{CI})\end{array}$ & & 374 & & 378 & 100 & $2,09[1,04-4,22]$ & \\
\hline $\begin{array}{l}\text { Tổng mẫu } \\
\text { methyl }\end{array}$ & 126 & & 93 & & & & $\begin{array}{lll}0,1 & 1 & 10 \\
{[K i ́ c h} & \text { thước khối u nhỏ] } & \text { OR } \\
\text { [Kích thước khối u lớn] }\end{array}$ \\
\hline
\end{tabular}

Tính bất đồng nhất: $\mathrm{Tau}^{2}=-0,006 \mathrm{Chi}^{2}=23,16 \mathrm{df}=7(\mathrm{P}=0,0016), \mathrm{I}^{2}=69,74 \%$

Phân tích tổng ảnh hưởng: $\mathrm{Z}=2,81$

$(\mathrm{P}=0,005)$

Hình 9. Kết quả phân tích tính chất methyl hóa vượt mức vùng promoter gen GSTP1 trên bộ dữ liệu 8 nghiên cứu về bệnh ung thư vú, xét yếu tố kích thước khối u (lớn hay nhỏ) 


\begin{tabular}{|c|c|c|c|c|c|c|c|}
\hline \multirow{2}{*}{$\begin{array}{l}\text { Công trình } \\
\text { nghiên cứu }\end{array}$} & \multicolumn{2}{|c|}{$\begin{array}{l}\text { Kích thước } \\
\text { khối u lớn }\end{array}$} & \multicolumn{2}{|c|}{$\begin{array}{l}\text { Kích thước } \\
\text { khối u nhỏ }\end{array}$} & \multirow{2}{*}{$\begin{array}{l}\text { Trọng } \\
\text { số }(\%)\end{array}$} & \multirow{2}{*}{$\begin{array}{c}\text { Chỉ số tỷ suất } \\
\text { chênh } \\
\text { Mố hình phân tích } \\
\text { bất biến, } 95 \% \text { CI }\end{array}$} & \multirow{2}{*}{$\begin{array}{c}\text { Chỉ số tỷ suất chênh } \\
\text { Mô hình phân tích bất biến, } 95 \% \text { CI }\end{array}$} \\
\hline & $\begin{array}{c}\text { Mẫu } \\
\text { methyl } \\
\text { hóa }\end{array}$ & $\begin{array}{l}\text { Tổng } \\
\text { mẫu }\end{array}$ & $\begin{array}{c}\text { Mẫu } \\
\text { methyl } \\
\text { hóa }\end{array}$ & $\begin{array}{l}\text { Tổng } \\
\text { mẫu }\end{array}$ & & & \\
\hline Shakeri (2016) & 15 & 39 & 12 & 36 & 26,95 & $1,25[0,48-3,22]$ & \\
\hline $\begin{array}{l}\text { Pongtheerat } \\
\text { (2011) }\end{array}$ & 3 & 12 & 6 & 28 & 9,58 & $1,22[0,25-5,98]$ & \\
\hline $\begin{array}{l}\text { Matuschek } \\
(2010)\end{array}$ & 6 & 11 & 6 & 57 & 11,37 & $10,2[2,37-43,81]$ & \\
\hline Sharma (2009) & 18 & 44 & 7 & 57 & 24,48 & $2,5[0,61-10,19]$ & \\
\hline Lasabova (2009) & 7 & 21 & 4 & 24 & 12,23 & $5,13[1,46-17,95]$ & \\
\hline Arai (2006) & 21 & 107 & 3 & 66 & 15,39 & $5,13[1,46-17,95]$ & \\
\hline $\begin{array}{l}\text { Tổng mẫu ( } 95 \% \\
\text { CI) }\end{array}$ & & 234 & & 268 & 100 & $3,01[1,87-4,85]$ & \\
\hline Tổng mẫu methyl & 70 & & 38 & & & & \\
\hline \multicolumn{7}{|c|}{ Tính bất đồng nhất: $\mathrm{Chi}^{2}=8,96 \mathrm{df}=5(\mathrm{P}=0,11), \mathrm{I}^{2}=44,21 \%$} & 1 \\
\hline \multicolumn{7}{|c|}{ Phân tích tổng ảnh hưởng: $\mathrm{Z}=4,54(\mathrm{P}<0,001)$} & 10 \\
\hline
\end{tabular}

Hình 10. Kết quả phân tích tính chất methyl hóa vượt mức vùng promoter gen GSTP1 trên bộ dữ liệu 6 nghiên cứu về bệnh ung thư vú, xét yếu tố kích thước khối u (lớn hay nhỏ) 


\begin{tabular}{|c|c|c|c|c|c|c|c|}
\hline \multirow{2}{*}{$\begin{array}{l}\text { Công trình } \\
\text { nghiên cứu }\end{array}$} & \multicolumn{2}{|c|}{$\begin{array}{l}\text { Hạch bạch } \\
\text { huyết (+) }\end{array}$} & \multicolumn{2}{|c|}{$\begin{array}{l}\text { Hạch bạch } \\
\text { huyết (-) }\end{array}$} & \multirow{2}{*}{$\begin{array}{c}\text { Trọng } \\
\text { số } \\
(\%)\end{array}$} & \multirow{2}{*}{$\begin{array}{l}\text { Chỉ số tỷ suất } \\
\text { chênh } \\
\text { Mô hình phân } \\
\text { tích bất biến, } \\
\text { 95\% CI }\end{array}$} & \multirow{2}{*}{$\begin{array}{l}\text { Chỉ số tỷ suất chênh } \\
\text { Mô hình phân tích bất biến, } 95 \% \text { CI }\end{array}$} \\
\hline & $\begin{array}{c}\text { Mẫu } \\
\text { methyl } \\
\text { hóa }\end{array}$ & $\begin{array}{l}\text { Tổng } \\
\text { mẫu }\end{array}$ & $\begin{array}{c}\text { Mẫu } \\
\text { methyl } \\
\text { hóa }\end{array}$ & $\begin{array}{l}\text { Tổng } \\
\text { mấu }\end{array}$ & & & \\
\hline Wu (2016) & 13 & 37 & 9 & 33 & 8,61 & $1,44[0,52-4,01]$ & \\
\hline Shakeri (2016) & 20 & 43 & 7 & 32 & 8,45 & $3,10[1,11-8,70]$ & \\
\hline Hafez (2015) & 41 & 77 & 48 & 103 & 25,61 & $1,30[0,72-2,36]$ & \\
\hline Jung (2013) & 7 & 29 & 3 & 31 & 4,19 & $2,97[0,69-12,83]$ & \\
\hline $\begin{array}{l}\text { Pongtheerat } \\
\text { (2011) }\end{array}$ & 7 & 17 & 2 & 21 & 2,94 & $6,65[1,16-38,19]$ & \\
\hline Matuschek (2010) & 10 & 37 & 3 & 32 & 4,63 & $3,58[0,89-14,41]$ & \\
\hline Sharma (2009) & 20 & 69 & 5 & 32 & 7,6 & $2,20[0,74-6,53]$ & \\
\hline Lasabova (2009) & 9 & 21 & 2 & 23 & 3,15 & $7,87[1,45-42,61]$ & \\
\hline Sunami (2008) & 15 & 54 & 8 & 76 & 10,07 & $3,27[1,27-8,40]$ & \\
\hline Arai (2006) & 13 & 60 & 11 & 112 & 11,73 & $2,54[1,06-6,09]$ & 0,1 \\
\hline Shinozaki (2005) & 22 & 81 & 10 & 70 & 13,04 & $2,24[0,98-5,13]$ & [Hạch bạch huŷ́t âm] OR [Hạch bạch huyết dương] \\
\hline $\begin{array}{l}\text { Tổng mẫu (95\% } \\
\text { CI) }\end{array}$ & & 525 & & 565 & 100 & $2,29[1,70-3,07]$ & \\
\hline Tổng mẫu methyl & 177 & & 108 & & & & \\
\hline
\end{tabular}

Hình 11. Kết quả phân tích tính chất methyl hóa vượt mức vùng promoter gen GSTP1 trên bộ dữ liệu 11 nghiên cứu về bệnh ung thư vú, xét yếu tố xuất hiện hạch bạch huyết (có hoặc không) 


\begin{tabular}{|c|c|c|c|c|c|c|c|}
\hline \multirow{2}{*}{$\begin{array}{l}\text { Công trình } \\
\text { nghiên cứu }\end{array}$} & \multicolumn{2}{|c|}{$\begin{array}{l}\text { HER dương } \\
\text { tính }\end{array}$} & \multicolumn{2}{|c|}{ HER âm tính } & \multirow{2}{*}{$\begin{array}{l}\text { Trông } \\
\text { số (\%) }\end{array}$} & \multirow{2}{*}{$\begin{array}{l}\text { Chỉ số tỷ suất chênh } \\
\text { Mô hình phân tích bất } \\
\text { biến, 95\% CI }\end{array}$} & \multirow{2}{*}{$\begin{array}{c}\text { Chỉ số tỷ suất chênh } \\
\text { Mô hình phân tích bất biến, } 95 \% \\
\text { CI }\end{array}$} \\
\hline & $\begin{array}{l}\text { Mẫu } \\
\text { methy } \\
\text { l hóa }\end{array}$ & $\begin{array}{l}\text { Tổng } \\
\text { mẫu }\end{array}$ & $\begin{array}{c}\text { Mẫu } \\
\text { methy } \\
\text { l hóa }\end{array}$ & $\begin{array}{l}\text { Tổng } \\
\text { mẫu }\end{array}$ & & & \\
\hline Bhat (2017) & 6 & 12 & 13 & 39 & 7 & $2,00[0,54-7,43]$ & \\
\hline Wu (2016) & 11 & 36 & 11 & 34 & 11,83 & $0,92[0,33-2,52]$ & + \\
\hline Thao (2015) & 20 & 39 & 24 & 76 & 19,2 & $2,28[1,03-5,03]$ & \\
\hline Jung (2013) & 4 & 29 & 6 & 29 & 6,28 & $0,61[0,15-2,45]$ & \\
\hline $\begin{array}{l}\text { Pongtheerat } \\
\text { (2011) }\end{array}$ & 12 & 28 & 3 & 15 & 5,58 & $3,00[0,69-13,05]$ & \\
\hline Matuschek (2010) & 7 & 17 & 4 & 44 & 6,06 & $7,00[1,71-28,68]$ & \\
\hline Sharma (2009) & 11 & 23 & 14 & 78 & 12,01 & $4,19[1,54-11,41]$ & \\
\hline Lasabova (2009) & 10 & 40 & 1 & 5 & 2,27 & $1,33[0,13-13,37]$ & \\
\hline Sunami (2008) & 12 & 29 & 10 & 78 & 12,22 & $4,80[1,78-12,96]$ & \\
\hline Shinozaki (2005) & 19 & 31 & 33 & 112 & 17,55 & $3,79[1,65-8,68]$ & $<$ \\
\hline $\begin{array}{l}\text { Tổng mẫu }(95 \% \\
\text { CI) }\end{array}$ & & 284 & & 510 & 100 & $2,50[1,77-3,52]$ & 10 \\
\hline Tổng mẫu methyl & 112 & & 119 & & & & số HER âm tinhl] OR [Chỉ số HER drơng tính] \\
\hline
\end{tabular}

Hình 12. Kết quả phân tích tính chất methyl hóa vượt mức vùng promoter gen GSTPI trên bộ dữ liệu 10 nghiên cứu về bệnh ung thư vú, xét yếu tố biểu hiện HER2 (có hoặc không) 


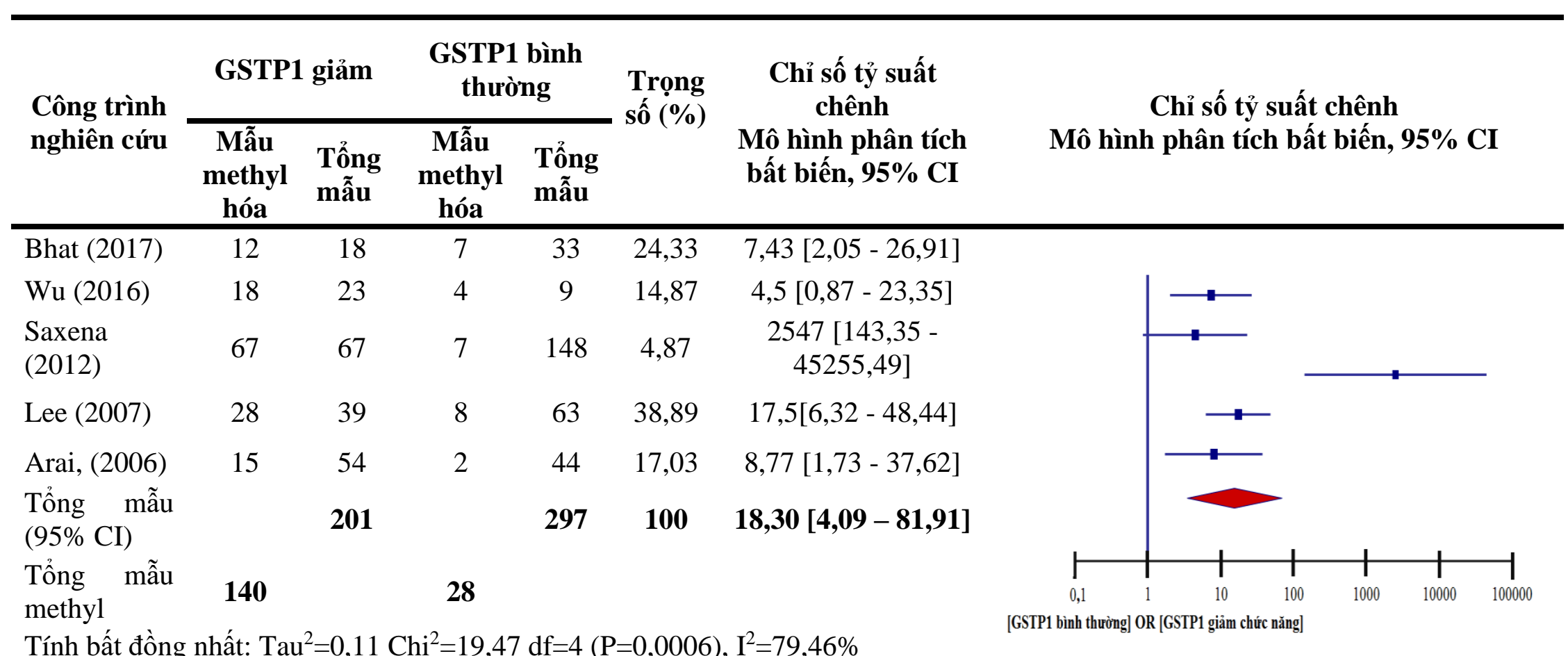

Phân tích tổng ảnh hưởng: $\mathrm{Z}=3,80$

$(\mathrm{P}<0,001)$

Hình 13. Kết quả phân tích tính chất methyl hóa vượt mức vùng promoter gen GSTPl trên bộ dữ liệu 5 nghiên cứu về bệnh ung thư vú, xét yếu tố tăng hoặc giảm chức năng protein GSTP1 


\section{Tài liệu tham khảo}

Arai, T., Miyoshi, Y., Kim, S. J., Taguchi, T., Tamaki, Y., \& Noguchi, S. (2006). Association of GSTP1 CpG islands hypermethylation with poor prognosis in human breast cancers. Breast Cancer Research and Treatment, 100(2), 169-176.

Bhat, A., Masood, A., Wani, K. A., Bhat, Y. A., Nissar, B., Khan, N. S., \& Ganai, B. A. (2017). Promoter methylation and gene polymorphism are two independent events in regulation of GSTP1 gene expression. Tumor Biology, 39(4), 1-11. doi:10.1177/1010428317697563.

Dejeux, E., Rønneberg, J. A., Solvang, H., Bukholm, I., Geisler, S., Aas, T., \& Tost, J. (2010). DNA methylation profiling in doxorubicin treated primary locally advanced breast tumours identifies novel genes associated with survival and treatment response. Molecular Cancer, 9(1), Article 68.

Ferlay, J., Soerjomataram, I., Dikshit, R., Eser, S., Mathers, C., Rebelo, M., ... Bray, F. (2015). Cancer incidence and mortality worldwide: Sources, methods and major patterns in GLOBOCAN 2012. International Journal of Cancer, 136(5), E359-E386.

Ford, M. E., \& Kelly, P. A. (2005). Conceptualizing and categorizing race and ethnicity in health services research. Health Services Research, 40(5p2), 1658-1675.

Globocan. (2012). Latest world cancer statistics Global cancer burden rises to 14.1 million new cases in 2012: Marked increase in breast cancers must be addressed. Retrieved October 10, 2017, from International Agency for Research on Cancer website: https://www.iarc.who.int/wp-content/uploads/2018/07/pr223_E.pdf

Hafez, M. M., Al-Shabanah, O. A., Al-Rejaie, S. S., Al-Harbi, N. O., Hassan, Z. K., Alsheikh, A., ... Sayed-Ahmed, M. M. (2015). Increased hypermethylation of glutathione Stransferase P1, DNA-binding protein inhibitor, death associated protein kinase and paired box protein-5 genes in triple-negative breast cancer Saudi females. Asian Pacific Journal of Cancer Prevention, 16(2), 541-549.

Haidich, A. B. (2010). Meta-analysis in medical research. Hippokratia, 14(Suppl 1), 29-37.

Higgins, J. P., Thompson, S. G., Deeks, J. J., \& Altman, D. G. (2003). Measuring inconsistency in meta-analyses. BMJ: British Medical Journal, 327(7414), 557-560.

Hoque, M. O., Feng, Q., Toure, P., Dem, A., Critchlow, C. W., Hawes, S. E., ... \& Yu, M. (2006). Detection of aberrant methylation of four genes in plasma DNA for the detection of breast cancer. Journal of Clinical Oncology, 24(26), 4262-4269.

Hughes, E. G. (1996). Systematic literature review and meta-analysis. Seminars in Reproductive Endocrinology, 14(2), 161-169.

Isgor, Y. G., \& Isgor, B. S. (2011). Kinases and glutathione transferases: Selective and sensitive targeting. Frontiers in Biology, 6(2), 156-169. 
Jerónimo, C., Costa, I., Martins, M. C., Monteiro, P., Lisboa, S., Palmeira, C., ... Lopes, C. (2003). Detection of gene promoter hypermethylation in fine needle washings from breast lesions. Clinical Cancer Research, 9(9), 3413-3417.

Jones, P. A., \& Baylin, S. B. (2002). The fundamental role of epigenetic events in cancer. Nature Reviews Genetics, 3(6), 415-428.

Jung, E. J., Kim, I. S., Lee, E. Y., Kang, J. E., Lee, S. M., Kim, D. C., ... Park, S. T. (2013). Comparison of methylation profiling in cancerous and their corresponding normal tissues from Korean patients with breast cancer. Annals of Laboratory Medicine, 33(6), 431-440.

Klajic, J., Fleischer, T., Dejeux, E., Edvardsen, H., Warnberg, F., Bukholm, I., ... Kristensen, V. N. (2013). Quantitative DNA methylation analyses reveal stage dependent DNA methylation and association to clinico-pathological factors in breast tumors. $B M C$ Cancer, 13(1), Article 456.

Lasabova, Z., Tilandyova, P., Kajo, K., Zubor, P., Burjanivova, T., Danko, J., \& Plank, L. (2010). Hypermethylation of the GSTP1 promoter region in breast cancer is associated with prognostic clinicopathological parameters. Neoplasma, 57(1), 35-40.

Lee, J. S. (2007). GSTP1 promoter hypermethylation is an early event in breast carcinogenesis. Virchows Archiv, 450(6), 637-642.

Matuschek, C., Bölke, E., Lammering, G., Gerber, P. A., Peiper, M., Budach, W., ... Bojar, H. (2010). Methylated APC and GSTP1 genes in serum DNA correlate with the presence of circulating blood tumor cells and are associated with a more aggressive and advanced breast cancer disease. European Journal of Medical Research, 15(7), 277-286.

Moher, D., Liberati, A., Tetzlaff, J., Altman, D. G., \& Prisma Group. (2009). Preferred reporting items for systematic reviews and meta-analyses: The PRISMA statement. PLoS Medicine, 6(7), Article e1000097.

Müller, H. M., Widschwendter, A., Fiegl, H., Ivarsson, L., Goebel, G., Perkmann, E., ... Widschwendter, M. (2003). DNA methylation in serum of breast cancer patients. Cancer Research, 63(22), 7641-7645.

Park, S. Y., Kwon, H. J., Lee, H. E., Ryu, H. S., Kim, S. W., Kim, J. H., ... Kang, G. H. (2011). Promoter $\mathrm{CpG}$ island hypermethylation during breast cancer progression. Virchows Archiv, 458(1), 73-84.

Parrella, P., Poeta, M. L., Gallo, A. P., Prencipe, M., Scintu, M., Apicella, A., ... Rabitti, C. (2004). Nonrandom distribution of aberrant promoter methylation of cancer-related genes in sporadic breast tumors. Clinical Cancer Research, 10(16), 5349-5354.

Phuong, T. K., Thao, D. T. P., Thuan, L. D., \& Thuy, L. H. A. (2016). Sự methyl hóa vượt mức tại đảo $\mathrm{CpG}$ thuộc vùng promoter của gen GSTP1 là một đặc tính đặc trưng của bệnh ung thư vú người Việt Nam [The excessive methylation at $\mathrm{CpG}$ island in the promoter region of the GSTP1 gene is a characteristic feature of Vietnamese breast cancer]. Tap chí Phát triển Khoa học và Công nghệ, 18(3T), 99-104. 
Pongtheerat, T., Pakdeethai, S., Purisa, W., Chariyalertsak, S., \& Petmitr, S. (2011). Promoter methylation and genetic polymorphism of glutathione S-transferase P1 gene (GSTP1) in Thai breast-cancer patients. Asian Pacific Journal of Cancer Prevention, 12(10), 27312734.

Rønneberg, J. A., Tost, J., Solvang, H. K., Alnaes, G. I., Johansen, F. E., Brendeford, E. M., ... Gabrielsen, O. S. (2008). GSTP1 promoter haplotypes affect DNA methylation levels and promoter activity in breast carcinomas. Cancer Research, 68(14), 5562-5571.

Russo, M. W. (2007). How to review a meta-analysis. Gastroenterology \& Hepatology, 3(8), 637-642.

Ryan, R. (2014). Heterogeneity and subgroup analyses in Cochrane Consumers and Communication Group reviews: Planning the analysis at protocol stage. Retrieved November 15, 2017, from Cochrane Consumers and Communication Review Group webite: http://cccrg.cochrane.org

Saxena, A., Dhillon, V. S., Shahid, M., Khalil, H. S., Rani, M., Das, T. P., ... Shukla, N. K. (2012). GSTP1 methylation and polymorphism increase the risk of breast cancer and the effects of diet and lifestyle in breast cancer patients. Experimental and Therapeutic Medicine, 4(6), 1097-1103.

Senior, P. A., \& Bhopal, R. (1994). Ethnicity as a variable in epidemiological research. BMJ: British Medical Journal, 309(6950), 327-330.

Shakeri, H., Gharesouran, J., Fakhrjou, A., Esfahani, A., \& Ardebili, S. M. M. (2016). DNA methylation assessment as a prognostic factor in invasive breast cancer using methylation-specific multiplex ligation dependent probe amplification. EXCLI Journal, $15,11-20$.

Shargh, S. A., Hosseini, Z. M., \& Sakizli, M. (2011). Evaluation of methylation status in glutation S-transferase P1 (GSTP1) gene promoter in human breast cancer and its relation to tumor grade and stage. Scientific Research and Essays, 6(27), 5741-5749.

Sharma, G., Mirza, S., Yang, Y. H., Parshad, R., Hazrah, P., Gupta, S. D., \& Ralhan, R. (2009). Prognostic relevance of promoter hypermethylation of multiple genes in breast cancer patients. Analytical Cellular Pathology, 31(6), 487-500.

Shinozaki, M., Hoon, D. S., Giuliano, A. E., Hansen, N. M., Wang, H. J., Turner, R., \& Taback, B. (2005). Distinct hypermethylation profile of primary breast cancer is associated with sentinel lymph node metastasis. Clinical Cancer Research, 11(6), 2156-2162.

Sturgeon, S. R., Balasubramanian, R., Schairer, C., Muss, H. B., Ziegler, R. G., \& Arcaro, K. F. (2012). Detection of promoter methylation of tumor suppressor genes in serum DNA of breast cancer cases and benign breast disease controls. Epigenetics, 7(11), 1258-1267.

Sunami, E., Shinozaki, M., Sim, M. S., Nguyen, S. L., Vu, A. T., Giuliano, A. E., \& Hoon, D. S. (2008). Estrogen receptor and HER2/neu status affect epigenetic differences of tumorrelated genes in primary breast tumors. Breast Cancer Research, 10(3), Article R46. 
Tang, J., Zhou, Q., Zhao, F., Wei, F., Bai, J., Xie, Y., \& Huang, Y. (2015). Association of glutathione S-transferase T1, M1 and P1 polymorphisms in the breast cancer risk: a metaanalysis in Asian population. International Journal of Clinical and Experimental Medicine, 8(8), Article 12430.

Terry, M. B., McDonald, J. A., Wu, H. C., Eng, S., \& Santella, R. M. (2016). Epigenetic biomarkers of breast cancer risk: Across the breast cancer prevention continuum. Novel Biomarkers in the Continuum of Breast Cancer, 882, 33-68.

The Nordic Cochrane Centre (Cochrane). (2014). Review manager. Copenhagen: The Nordic Cochrane Centre.

Wang, T., Arifoglu, P., Ronai, Z. E., \& Tew, K. D. (2001). Glutathione S-transferase P1-1 (GSTP1-1) inhibits c-Jun N-terminal kinase (JNK1) signaling through interaction with the C terminus. Journal of Biological Chemistry, 276(24), 20999-21003.

Wu, L., Shen, Y., Peng, X., Zhang, S., Wang, M., Xu, G., ... Lu, C. (2016). Aberrant promoter methylation of cancer-related genes in human breast cancer. Oncology Letters, 12(6), 5145-5155.

Yamamoto, N., Nakayama, T., Kajita, M., Miyake, T., Iwamoto, T., Kim, S. J., ... Noguchi, S. (2012). Detection of aberrant promoter methylation of GSTP1, RASSF1A, and RAR $\beta 2$ in serum DNA of patients with breast cancer by a newly established one-step methylationspecific PCR assay. Breast Cancer Research and Treatment, 132(1), 165-173. 